\title{
The Structure and Dynamics of
}

\section{2-Dimensional Fluids in Swelling Clays}

\author{
Neal T. Skipper, ${ }^{\mathrm{a},}$, Peter A. Lock ${ }^{\mathrm{a}}$, James O Titiloye ${ }^{\mathrm{b}}$, Jan Swenson ${ }^{\mathrm{c}}$, Zakaria A Mirza ${ }^{\mathrm{a}}$, W. \\ Spencer Howells $^{\mathrm{d}}$, Felix Fernandez-Alonso ${ }^{\mathrm{d}}$ \\ a Department of Physics and Astronomy, University College London, Gower Street, London WC1E 6BT, UK. \\ ${ }^{b}$ Department of Chemical Engineering \& Applied Chemistry, Aston University, Birmingham, B4 7ET, UK. \\ ${ }^{c}$ Dept. of Applied Physics, Chalmers University of Technology, SE-412 96 Göteborg, Sweden. \\ ${ }^{d}$ ISIS Facility, Rutherford Appleton Laboratory, Chilton, Didcot, OX11 0QX, UK.
}

*Corresponding author. Tel. +44 207679 3526; fax +44 2076791360

Email address; $\underline{\text { n.skipper@ucl.ac.uk }}$

\begin{abstract}
The interlayer pores of swelling 2:1 clays provide an ideal 2-dimensional environment in which to study confined fluids. In this paper we discuss our understanding of the structure and dynamics of interlayer fluid species in expanded clays, based primarily on the outcome of recent molecular modelling and neutron scattering studies. Counterion solvation is compared with that measured in bulk solutions, and at a local level the cation-oxygen coordination is found to be remarkably similar in these two environments. However, for the monovalent ions the contribution to the first coordination shell from the clay surfaces increases with counterion radius. This gives rise to inner-sphere (surface)
\end{abstract}


complexes in the case of potassium and caesium. In this context, the location of the negative clay surface charge (ie arising from octahedral or tetrahedral substitution) is also found to be of major importance. The divalent cations, calcium and magnesium, eagerly solvate to form outer-sphere complexes. These complexes are able to pin adjacent clay layers together, and thereby prevent colloidal swelling. Confined water molecules are able to form hydrogen bonds to each other and to the clays surfaces. In this way their local environment relaxes close to the bulk water structure within two molecular layers of the clay surface. Finally, we discuss the way in which the simple organic molecules methane, methanol and ethylene glycol behave in the interlayer environment of hydrated clays. Quasi-elastic neutron scattering of isotopically labeled interlayer $\mathrm{CH}_{3} \mathrm{OD}$ and $\left(\mathrm{CH}_{2} \mathrm{OD}\right)$ in deuterated clay allows us to measure the diffusion of the methyl-groups in both the clay and liquid environments. We find that in the single-layer solvates the motion of the organic molecules is significantly retarded relative to the pure bulk liquids. In the two-layer solvates, however, the there is interesting competition between hydrophobic and hydrophilic interactions.

Keywords: Swelling Clay, Confined Fluid, Fluid Diffusion. 


\section{Introduction}

The interlayer pores of swelling 2:1 clays are the site of many important geochemical, environmental and industrial processes (Newman, 1987; North, 1990) These include the diagenetic reactions which are a major source of water in the earth's crust, ion exchange in soils and sedimentary rocks, and primary and tertiary migration of petroleum hydrocarbons. In addition, the hydration and dehydration of expandable clays is a continuing problem for the construction, waste containment and oil-well drilling industries. The swelling 2:1 clay minerals also provide an ideal arena in which to study the fundamental properties of confined 2-dimensional aqueous fluids.

2:1 clays layers are comprised of one sheet of octahedrally coordinated cations, such as $\mathrm{Mg}^{2+}$ or $\mathrm{Al}^{3+}$, sandwiched between two sheets of tetrahedral cations, such as $\mathrm{Si}^{4+}$ (figure 1). The two charge-neutral 2:1 clays, talc and pyropyllite, are hydrophobic and do not swell spontaneously in water and other polar solvents (Newman, 1987; Brindley and Brown, 1980; Sposito et al, 1999)). However, the clay sheets can acquire net negative charge when either the octahedral and/or tetrahedral cations are substituted by species of lower valence. This isomorphic replacement leads to a rich variety in the location and density of layer charges in 2:1 clay minerals. If we use generic tri- and di-octahedral structural formulae, $\left[\mathrm{T}_{3-\mathrm{x}} \mathrm{M}_{\mathrm{x}}\right]\left[\mathrm{Si}_{4-\mathrm{z}} \mathrm{Al}_{\mathrm{z}}\right] \mathrm{O}_{10}(\mathrm{OH})_{2}$ and $\left[\mathrm{D}_{2-\mathrm{x}} \mathrm{M}_{\mathrm{x}}\right]\left[\mathrm{Si}_{4-\mathrm{z}} \mathrm{Al}_{\mathrm{z}}\right] \mathrm{O}_{10}(\mathrm{OH})_{2}$, we can then identify some general classes of clay particles based on the total layer charge, $Q=x$ $+z$ : 
- Talcs \& pyrophyllite: $Q \sim 0.0$. Non-swelling hydrophobic clays.

- Smectites: $0.2<Q<0.6$. Swelling clays, individual platelet size $\sim \mu \mathrm{m}^{2}$.

- Vermiculites: $0.6<Q<0.9$. Swelling clays, individual platelet sizes $\sim \mathrm{mm}^{2}$.

- Illites \& Micas: $0.9<Q<1.0$. Non-swelling hydrophilic clays.

The smectites and vermiculites are therefore the swelling clays (Newman, 1987). In addition to the greater surface charge density among the vermiculites, these clays also possess a great fraction of tetrahedral charge substitution. This, we will see is important, as the tetrahedral charges are closer to the surface than the octahedral charges. For reference, examples of the smectites include: saponite, hectorite and laponite (trioctahedral), and; montmorillonite and beidellite (dioctahedral).

The negative layer charge in 2:1 clays is, in turn, balanced by exchangeable counterions such as $\mathrm{Na}^{+}, \mathrm{K}^{+}$and $\mathrm{Ca}^{2+}$. In broad terms, it is the tendency of these interlayer counterions to solvate that causes the clays to expand in the presence of water and other polar solvents (Brindley, 1966; Brindley and Brown, 1980; Lagaly, 1981; Sposito and Prost, 1982; Newman, 1987). In the first instance this expansion takes the form of a series of discrete steps, known as crystalline swelling (figure 2 and 3). Crystalline swelling is loosely associated with the formation of molecular layers of interlayer solvent, but is in fact more closely associated with the solvation by stages of the interlayer counterions themselves. In certain cases, crystalline swelling is followed by longer-range colloidal, or osmotic, swelling. In this regime the interparticle interactions 
are typically governed by continuum electrostatic forces (Norrish, 1954; Glaeser and Méring, 1968; Brindley and Brown, 1980; Sposito and Prost, 1982; Newman, 1987; Güven, 1992).

Within the two broad regimes of clay swelling there is in fact great complexity of solvation and expansion behaviour, reflecting the subtle balance between the various interparticle forces. For a given fluid, the nature of the clay-fluid interactions is mainly determined by: (i) the valence, radius and number density of the interlayer counterions, and; (ii) the number density and origin (octahedral or tetrahedral substitution) of the clay layer charges (Brindley and Brown, 1980; Newman, 1987). To illustrate the interplay between these interactions, we note that many Na-substituted montmorillonites expand macroscopically in water, while their $\mathrm{K}$ - and Ca-substituted analogues do not (Brindley and Brown, 1980; Newman, 1987). It is effects such as these that we seek to understand. We also point out at this stage that the dependence of clay hydration on the interlayer cation valence and surface charge density is mirrored in many other fields where solidsolution interfaces are present. Most notably, one can point to the numerous biochemical processes that depend on ion-selectivity in pores and at surfaces (Kuyucak et al, 2001).

In this contribution we first focus on the molecular nature of interlayer aqueous fluids, and the mechanisms of clay swelling. In terms of methodology, we draw attention to the symbiotic relationship between computer simulation and neutron scattering, which allows detailed understanding of both the confined and bulk fluids (Enderby and Neilson, 1981; Sposito and Prost, 1982; Enderby et al, 1987; Ohtaki and Radnai, 1993). We first 
discuss the speciation of the interlayer counterions, and compare the local coordination in clays with that in the bulk. In addition to ion valence and radius, we will note that the location of the negative clay surface charge (ie arising from octahedral or tetrahedral substitution) is also of major importance. We then focus on the hydrogen-bonding among the interlayer water molecules, and find that their local environment relaxes close to the bulk within two molecular layers of the clay surface. Finally, we discuss the way in which the simple organic molecules methane, methanol and glycol behave in the interlayer environment of hydrated clays. Here there is interesting competition between hydrophobic and hydrophilic interactions. Quasi-elastic neutron scattering of isotopically labeled interlayer $\mathrm{CH}_{3} \mathrm{OD}$ and $\left(\mathrm{CH}_{2} \mathrm{OD}\right)_{2}$ has allowed us to measure the diffusion of the methyl-groups.

As a warning, we should point out that the systems we discuss are idealized, particularly in terms of the assumed homogeneity of the clay layers and hydration state. It is in fact probable that the hydration state of real smectites in particular will not be homogenous (Berend et al, 1995; Cases et al, 1997). In addition, the hydration state depends not only on the humidity conditions but also on the history of the water-clay system (Wilson et al, 2004). 


\section{Methods}

In this paper we will mainly discuss the results from molecular modelling and neutron scattering studies of clay-fluid systems. Here we limit our scope to quite brief overviews of these techniques, and refer interested readers to more detailed reviews.

\subsection{Molecular Modelling}

Molecular modelling of condensed matter aims to calculate the observable properties of systems in which the particles interact through a specified set of potential energy functions (Allen and Tildesley, 1987; Frenkel and Smit, 1996). Such computational techniques are proving particularly effective in providing detailed microscopic understanding of aqueous and organic liquids and the clay-fluid systems, and have helped to resolve many fundamental questions in this field (Kubicki and Bleam, 1998; Teppen et al 1998, Sposito et al, 1999; Cygan, 2001; Cygan et al, 2004a; ChavezPaez et al, 2001a, 2001b; Hensen and Smit, 2002; Malikova et al, 2004; Marry et al 2003, 2004; Park and Sposito, 2000, 2002, 2003; Titiloye and Skipper 2001, 2005; Pintore et al 2001, Poirion et al, 2003).

In this article we are concerned primarily with the statistical mechanical properties of liquids confined within clays. For a practical reason (current computer power) we must therefore concentrate on classical simulations using empirical pair interaction potentials of the type given in equation 1 . We note, however, that there is an extensive literature on quantum mechanical studies of clay systems, using ab initio and 
semi-empirical techniques (Delville, 1991, 1992, 1993a, 1993b; Bleam, 1993; Tossell, 1995; Cygan, 2001; Boek and Sprik 2003).

To model a clay-fluid-cation system at the empirical level we require six sets of interaction potentials: fluid-fluid, fluid-cation, fluid-clay, cation-cation, cation-clay, and clay-clay. The current consensus in the context of aqueous fluids is that the quality of first of these terms is paramount, and we therefore start with a brief discussion of models for liquid water.

A number of potential models have been proposed for the interaction between two water molecules in the liquid state (Jorgensen et al, 1983; Finney et al, 1986; Watanabe and Klein, 1989; Mahoney and Jorgensen, 2000). One of the most widely used in the current context is known as TIP4P (Jorgensen et al, 1983; Vlot et al, 1999; Mahoney and Jorgensen, 2000). This model places four interaction sites on each molecule, corresponding to the oxygen $(\mathrm{O})$ and hydrogen $(\mathrm{H})$ atoms, and a charge site $(\mathrm{M})$ located on the $\mathrm{C}_{2}$ axis of the molecule. The interaction energy between two sites on different molecules then takes the form:

$$
u_{i j}\left(r_{i j}\right)=\frac{q_{i} q_{j}}{r_{i j}}+4 \varepsilon_{i j}\left[\left(\frac{\sigma_{i j}}{r_{i j}}\right)^{12}-\left(\frac{\sigma_{i j}}{r_{i j}}\right)^{6}\right]
$$

where $r_{\mathrm{ij}}$ is the separation between sites $i$ and $j . q_{\mathrm{i}}, \varepsilon_{\mathrm{ij}}$, and $\sigma_{\mathrm{ij}}$ are empirical parameters representing the partial charges, binding energy and contact separation respectively. The total interaction energy between two molecules is then the sum over all different intermolecular pairs of sites. 
We see that the TIP4P functional form is a Coulombic (electrostatic) interaction with a Lennard-Jones potential. In the TIP4P molecule the $\mathrm{HOH}$ bond angle is $104.52^{\circ}$, and the site-site distances $r_{\mathrm{OH}}=0.09572 \mathrm{~nm}$ and $r_{\mathrm{OM}}=0.015 \mathrm{~nm}$. The "partial charge", $q_{\mathrm{H}}$, on each hydrogen atom is $0.52 \mathrm{e}$, and $q_{\mathrm{M}}=-1.04 \mathrm{e}, \varepsilon_{\mathrm{oo}}=0.6487 \mathrm{kJmol}^{-1}$ and $\sigma_{\mathrm{oo}}=0.3154$ $n m$. The effective nature of these pair-wise terms becomes clear when one notes that the dipole moment of a TIP4P molecule is $2.18 \mathrm{D}$, compared with $1.85 \mathrm{D}$ for a real isolated water molecule.

The TIP4P model was obtained by refining the parameters in equation 1 by reference to thermodynamic and X-ray data for liquid water at STP. Importantly, the TIP4P model reproduces the density of bulk water, at STP (Jorgensen et al, 1983) and beyond (Brodholt and Wood, 1993; Siqueira et al, 1997). However, because the parameters were fitted to data for bulk water at STP, it might be expected to be less apposite in confined, non-tetrahedral, environments.

The intermolecular interactions shown in equation 1 are known as "non-bonding" terms. In fact, the TIP4P model (and many of those currently used to represent claywater-cation systems) assume that each molecule is a rigid entity. If one wanted to include "bonding" intramolecular terms, such as bond-bending or stretching, then these would appear as a sum over sites on the same molecule (Allen and Tildesley, 1987; Frenkel and Smit, 1996). An important development in this context has been the recent release of the CLAYFF molecular models by Cygan et al (2004b), since they are a selfconsistent potential set that include intramolecular bond flexibility terms which are suitable for a wide range of clay minerals and interlayer species. 
The TIP4P model forms part of a complete set of models for studying aqueousorganic fluids, the so-called OPLS potential parameters (Jorgensen, 1981, 1984; Jorgensen et al, 1983). Likewise, there are numerous potential functions available to describe the interactions of ions with TIP4P water and similar water models. These models have been collated, and compared with experimental data by, for example, Enderby and Neilson (1981), Neilson and Enderby (1989) and Ohtaki and Radnai (1993). The general conclusion is that the hydration of monovalent ions (such as $\mathrm{Li}^{+}, \mathrm{Na}^{+}$, and $\mathrm{K}^{+}$) can be well represented by rigid molecule effective pair potential models. Small diand trivalent cations (such as $\mathrm{Mg}^{2+}$ and $\mathrm{Al}^{3+}$ ) are more problematic (Bounds, 1985; Greathouse et al, 2000). These ions are strongly polarising, and may therefore require flexible/polarisable model of the solvent molecules (Lybrand and Kollmann, 1985; Smith and Haymet, 1992).

Within the realm of atomistic empirical models there are two common routes to fluid-clay interaction potential functions (Bleam, 1993; Kubicki and Bleam, 1998; Cygan, 2001, 2004b), (i) fitting to ab initio potential energy surface calculations (Delville, 1991, 1992), and (ii) direct transfer of parameters from fluid-fluid potential functions (Skipper et al, 1991b, 1995a). In either case, the functional form should be consistent with the choice of fluid-fluid interactions, and be able to represent octahedral and/or tetrahedral substitution within the clay sheet.

Two methods of computer simulation are currently available to calculate the equilibrium thermodynamic properties of a system in which the particles interact through a set of potential energy functions: Monte Carlo and molecular dynamics (Allen and 
Tildesley, 1987; Frenkel and Smit, 1996). Both methods can be used to calculate timeaveraged quantities, such as the structure and density.

The structural properties of the interlayer region are traditionally visualised in terms of the particle density profiles normal to the clay surfaces, $\rho_{\alpha}(z)$, and the radial distribution functions, $g_{\alpha \beta}(r)$.

$$
\rho_{\alpha}(z)=\frac{c_{Z}}{N_{\alpha}} \frac{d n_{\alpha}}{d z}
$$

where $c_{Z}$ is the clay layer-layer spacing, $N_{\alpha}$ the total number of particles of type $\alpha$, and $d n_{\alpha}$ is the average number of particles of type $\alpha$ lying between $z$ and $z+d z$, and;

$$
g_{\alpha \beta}(r)=\frac{1}{4 \pi \rho_{\beta} r^{2}} \frac{d n_{\alpha \beta}}{d r}
$$

where $\rho_{\beta}$ is the number density of species $\beta$, and $d n_{\alpha \beta}$ is the average number of particles of type $\beta$ lying at distances $r$ to $r+d r$ from a particle of type $\alpha$. For a given pair of particles, $g_{\alpha \beta}(r)$ has an asymptotic value of 1 . This may cause problems when we want to compare local structure around identical particles in environments of different average density, for example clays and the bulk. In such cases the radial density may be more appropriate;

$$
G_{\alpha \beta}(r)=\frac{d n_{\alpha \beta}}{d r} .
$$


The coordination number (ie average number of nearest neighbours) of particles of type $\beta$ around a particle of type $\alpha$ is given by;

$$
n_{\alpha \beta}(r)=\int_{r_{1}}^{r_{2}} G_{\alpha \beta}(r) d r
$$

where $r_{1}$ and $r_{2}$ are the limits that encompass the first solvation shell.

As we have seen above, both Monte Carlo and molecular dynamics methods can provide time-independent information about the system. Molecular dynamics, though more time consuming, can also give time-dependent quantities, such as diffusion coefficients, calculated directly from the trajectories of the particles. In the current context, an important example relates to the diffusion (mobilities) of the interlayer species. If we consider motion in $n$-dimensions, diffusion coefficients can be obtained directly from the velocity autocorrelation function;

$$
D_{\text {trans }}=\frac{1}{n} \int_{0}^{\infty} d t\langle v(t) \cdot v(0)\rangle
$$

where $D_{\text {trans }}$ is the translational self-diffusion coefficient of the $n$ particles of interest, and $v(t)$ is the velocity at time $t$. The corresponding Einstein relation, valid at long-times, relates the self-diffusion constant to the mean square displacement of each particle as a function of time;

$$
2 t D_{\text {trans }}=\frac{1}{n}\left\langle|r(t)-r(0)|^{2}\right\rangle
$$

With modern computers, used in conjunction with empirical interaction functions 
such as those described here, it is possible to calculate the properties of simulation cells containing up to a few thousands of particles, in a range of thermodynamic ensembles (Frenkel and Smit, 1996). In the case of a clay-water-cation system, the cell might contain a $20 \AA \times 20 \AA$ section of clay sheet, 6 cations, and 64 water molecules, such as that shown in figure $2 \mathrm{a}$. If such a system were to be studied in isolation edge effects would, of course, dominate. This may be desirable, depending on context, but in general the small simulation cell is disguised so that it looks like an infinite system. To do this the simulation cell is usually repeated infinitely in all three directions, using so-called periodic boundary conditions (Allen and Tildesley, 1987; Frenkel and Smit, 1996). It is then, in principle, a question of running the simulation for long enough to obtain meaningful averages of the quantities of interest. However, a practical limit for the duration of a complete molecular dynamics simulation is of the order 10ns.

Detailed comparison with experimental data has now given us confidence in the results derived from molecular modelling. For example, the layer spacing and water content can now be calculated via Grand Canonical constant chemical potential ensemble simulations, in which the chemical potential of the external water reservoir is fixed. (Allen and Tildesley, 1987; Delville, 1991, 1992; Frenkel and Smit, 1996; Karaborni et al., 1996; Schroll and Smith, 1999; Chávez-Páez et al, 2001a, 2001b; Hensen and Smit, 2002; Porion et al, 2003). As an example, Smith (1998), Chávez-Páez et al (2001a and 2001b) and Shroll and Smith (1999) have used Grand Canonical ensemble calculations to study Na-, Ca- and Cs-substituted Wyoming montmorillonites. They are then able to calculate the clay swelling disjoining pressure (and equilibrium water content) and free 
energy as a function of clay layer spacing. The mechanically stable hydrates are those for whom the swelling pressure intersect, with negative slope, corresponds to the applied pressure ( 1 bar). These can be seen as the arrows in figure 4 . In sodium Wyoming montmorillonite, for example, stable distances are predicted to be $10.2,12.2,15.7$ and

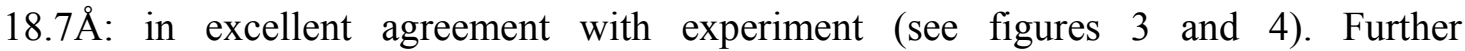
encouragement is also provided by detailed comparison with experimental interlayer structure, derived from X-ray and neutron diffraction. For example, Park and Sposito (2000, 2002) have excellent agreement at both the partial (ie site specific) radial distributions and partial density profile levels.

In this paper we present Monte Carlo (MC) simulations of hydrated hectorites of structural formula $\left[\mathrm{Mg}_{5.25} \mathrm{Li}_{0.75}\right]\left[\mathrm{Si}_{8}\right] \mathrm{O}_{20}(\mathrm{OH})_{4}^{-0.75}+0.75 \mathrm{M}^{+}+\mathrm{n}\left(\mathrm{H}_{2} \mathrm{O}\right)$. We choose this clay, as the charge substitution is entirely in the octahedral cation sheet, at the centre of the clay platelets. The simulation cell contains 24 units of this composition, and therefore comprises a $31.68 \times 36.56 \AA$ clay slab and 18 cations. Simulations were conducted using the method of de Carvalho and Skipper (2001), and employs as an ensemble an isothermal closed system where a uniaxial compacting stress is applied normal to the clay sheets. The potential model used is that Chandrasekhar et al (1984) and Boek et al. (1995b), and had the functional form given in equation 1. 


\subsection{Neutron Scattering}

The generic advantages of neutron scattering as a probe for studying clay-fluid interactions will be explained shortly. In brief, the neutron scattering properties of the atoms in these systems allow us to obtain both detailed structural and dynamical information over length and time-scales comparable with those accessible by computer simulation, and complementary to those of other experimental techniques (Sposito and Prost, 1984; Enderby and Neilson, 1981).

First, the light elements, such as hydrogen, carbon, nitrogen and oxygen, which predominate in pore fluids, scatter neutrons strongly (table 1). In addition, coherent neutron scattering lengths are isotope dependent. Isotopic substitution can therefore be used in conjunction with difference analysis to obtain a very detailed picture of the environment around a particular labelled species (Cebula et al, 1979; Hawkins and Egelstaff, 1980; Skipper et al, 1991b, 1994, 1995c; Williams et al 1998, Powell et al 1998). In particular, we can obtain both $\rho_{\alpha}(z)$ and $g_{\alpha \beta}(r)$ (equations 2 and 3; Park and Sposito, 2000). Suitable elements for this treatment include hydrogen, calcium and nitrogen.

Second, hydrogen has much the largest incoherent neutron scattering crosssection. The self-motion of specific protons can therefore be studied by quasi-elastic neutron scattering (QENS) in conjunction with selective substitution of hydrogen for deuterium (Cebula et al 1981; Tuck et al, 1984; Swenson et al, 2000). The time-scale that can be accessed through quasi-elastic neutron scattering is about $2-40 \mathrm{ps}$. This 
allows determination of translational diffusion coefficients and rotational correlation times for interlayer fluid species in clays (Cebula et al, 1979; Sposito and Prost, 1982; Tuck et al, 1984; Swenson et al, 2000). The experimental quantity that is extracted from a QENS experiment is the incoherent dynamic structure factor $S_{i n c}(\mathbf{Q}, \omega)$. This function can be expressed as a convolution of three terms (Bee, 2003):

$$
S_{\text {inc }}(\mathbf{Q}, \omega)=e^{-1 / 3 Q^{2}\left\langle u^{2}\right\rangle} S_{\text {inc }}^{\text {trans }}(\mathbf{Q}, \omega) \otimes S_{\text {inc }}^{\text {rot }}(\mathbf{Q}, \omega)
$$

Where $\hbar \mathbf{Q}$ is the momentum transfer and $\hbar \omega$ the energy transfer to the neutron. The first term is the Debye-Waller factor in which $\left\langle u^{2}\right\rangle$ is the mean square displacement. The second and third terms are the translational and rotational incoherent dynamic structures respectively.

For times which are long compared to the mean time between atomic collisions translation is governed by the diffusion process, and solution of Fick's Law results in a translational incoherent scattering function of the form (Squires, 1978; Hempelmann, 2000):

$$
S_{\text {inc }}^{\text {trans }}(Q, \omega)=\frac{1}{\pi} \frac{\hbar D_{\text {trans }} Q^{2}}{\left(\hbar D_{\text {trans }} Q^{2}\right)^{2}+(\hbar \omega)^{2}}
$$

where $D_{\text {trans }}$ is the translational diffusion coefficient. The translational incoherent dynamic structure factor is therefore a Lorentzian function with a half width at half maximum given by 


$$
\Lambda(Q)=\hbar D_{\text {trans }} Q^{2}
$$

For shorter times, the Gaussian jump-length distribution model of Tuck et al (1985) gives;

$$
\Lambda(Q)=\frac{2 \hbar}{\tau_{\text {trans }}}\left[1-\exp \left(-Q^{2}\left\langle l^{2}\right\rangle / 2\right)\right]
$$

where $\tau_{\text {trans }}$ is an average translational residence time and $\left\langle l^{2}\right\rangle$ is the mean square jump length. The translational diffusion coefficient (in 3-dimensions) is then given by;

$$
D_{\text {trans }}=\frac{\left\langle l^{2}\right\rangle}{6 \tau_{\text {trans }}}
$$

The simplest form for the rotational incoherent dynamic structure incoherent scattering function accounts for for rotational diffusion on the surface of a sphere of radius $R$ (Sears, 1966):

$$
S_{i n c}(\mathbf{Q}, \omega)=j_{0}^{2}(\mathbf{Q} \cdot \mathbf{R}) \delta(\omega)+\sum_{\mathrm{l}=1}^{\infty}(2 l+1) j_{l}^{2}(\mathbf{Q} \cdot \mathbf{R}) \frac{1}{\pi} \frac{D_{r o t} l(l+1)}{\left(D_{r o t} l(l+1)\right)^{2}+(\hbar \omega)^{2}}
$$

where $j_{l}(\mathbf{Q} \cdot \mathbf{R})$ is the $l^{\text {th }}$ spherical Bessel function, and $D_{\text {rot }}$ is the rotational diffusion coefficient. Typically we retain only the first two terms in equation $13(l=0,1)$. Such an approximation is justified because higher-order terms only have a significant contribution at larger momentum transfers than those probed in the experiments. Within the scope of this series truncation, the ( $\mathbf{Q}$-independent) half width at half maximum is then given by: 


$$
\Lambda(\mathbf{Q})=2 D_{r o t}=\frac{\hbar}{3 \tau_{r o t}}
$$

In this paper, we present quasi-elastic neutron scattering (QENS) experiments in which our main aim is to study the methyl-group mobility on methanol $\mathrm{CH}_{3} \mathrm{OD}$ and glycol $\left(\mathrm{CH}_{2} \mathrm{OD}\right)_{2}$ in deuterated Na-smectite and Na-vermiculite respectively. Experiments were conducted on the high-resolution inverted geometry IRIS neutron spectrometer (Howells 1996, Adams et al 2001), employing the method described by Swenson et al (2000). Using the pyrolitic graphite (002) analysers and a wavelength of about $6.6 \AA$ gives us a resolution of about $15 \mu \mathrm{eV}$, with an energy window of about $\pm 0.5 \mathrm{meV}$. The 51 detectors were grouped into 17 groups of three detectors in each case, giving a momentum transfer range of $0.46-1.84 \AA^{-1}$.

Our experimental data were corrected for absorption and background and empty can subtraction, as implemented using the standard analysis package MODES (Adams et al, 2001). This procedure provides us with the dynamic structure factors, $\mathrm{S}(\mathbf{Q}, \omega)$, which are here dominated by incoherent scattering from the protons. The dynamic structure factors were analysed using the Bayesian fitting routine QUASILINES a method which determines the most likely number of Lorentzian components required to fit the data. The fitting procedure allows us to determine the on $\mathbf{Q}$-dependence of the half width at half maximum of the Lorentzian components.

Two sodium substituted clays have been studied (table 2). The first is a vermiculite from Eucatex, Brazil, with dry composition: 
$\mathrm{Si}_{6.14} \mathrm{Mg}_{5.44} \mathrm{Al}_{1.66} \mathrm{Fe}_{0.50} \mathrm{Ti}_{0.12} \mathrm{Ca}_{0.12} \mathrm{O}_{20}(\mathrm{OH})_{4} \cdot 1.3 \mathrm{Na}^{+}$(Newman 1987). This clay occurs naturally as macroscopic crystalline flakes, typically with volume of the order $\mathrm{mm}^{3}-\mathrm{cm}^{3}$. The second clay is a smectite from Wyoming, USA, with dry composition: $\mathrm{Si}_{7.80} \mathrm{Mg}_{0.38} \mathrm{Al}_{3.48} \mathrm{Fe}_{0.34} \mathrm{O}_{20}(\mathrm{OH})_{4} \cdot 0.62 \mathrm{Na}^{+}$. This is Source Clay "SWy-1", obtained from the Source Clays Repository of the Clay Minerals Society (Newman, 1987). Because smectites occur only as micron scale particles, we prepared partially aligned cakes of SWy-1, by sedimenting the particles from suspension. Samples were then prepared by repeated soaking of the deuterated clays in isotopically enriched liquid methanol $\left(\mathrm{CH}_{3} \mathrm{OD}\right)$ and $60 \%$ by weight glycol $\left(\mathrm{DOCH}_{2} \mathrm{CH}_{2} \mathrm{OD}\right)$ in $\mathrm{D}_{2} \mathrm{O}$. The clays were air dried on filter paper before being placed in a flat-plate aluminium can with window thickness $2 \mathrm{~mm}$.

\section{Results and Discussion}

In this paper we discuss our understanding of the structure and dynamics of interlayer fluid species in expanded clays, based primarily on the outcome of recent molecular modelling and neutron scattering studies. Since our aim is to quantify the role of confinement by the clay sheets, the starting point is our knowledge of water and aqueous solutions, as exemplified in the reviews of Enderby and Neilson (1981), Finney et al (1986), Enderby et al (1987), Neilson and Enderby (1989), and Ohtaki and Radnai (1993). 


\subsection{Ion speciation in hydrated 2:1 clays}

In aqueous solution the hydration of metal ions is typically characterized by via the structure of the first (and second) solvation shells (Enderby et al, 1987; Ohtaki and Radnai, 1993). In this context key parameters are the coordination number (equation 5) and position of the first maximum in $g_{\mathrm{MO}}(r)$ (equation 3 and 4), which are accessible experimentally via neutron and X-ray diffraction techniques. Comparison of these data with their analogues for clay-water-cation systems therefore provides a ready measure of the effects of confinement. Further insight is then provided as we examine the relative proportions of the species identified in figure 5 (Sposito et al, 1999). The ability of an ion to hydrate, and thereby to graduate from inner- to outer- to diffuse-complex, has been identified as a key factor in the mobility of ions and the ability of clays to swell. We remind readers here that we expect a fundamental difference between tetrahedral (surface) and octahedral (embedded) clay charge sites.

Lithium hydrates strongly in water, to form a solvation shell of $\sim 5$ water molecules at an average $\mathrm{Li}^{+}-\mathrm{O}$ distance of around $1.95 \AA$ (Enderby et al, 1987), and with a solvation enthalpy of the order $-560 \mathrm{kJmol}^{-1}$. For this reason, we would expect lithium, of all the alkali ions, to hydrate in clay interlayers. Indeed, neutron diffraction studies of lithium-vermiculite (Skipper et al, 1995c) and lithium-smectite (Powell et al, 1998) hydrates have indicated that the lithium-water complex is robust, and that outer-sphere complexes are formed. Computer simulation studies (Boek et al 1995a, Chang et al, 1997; Park and Sposito, 2000) support this view. 
Sodium forms a solvation shell of $\sim 6$ water molecules at a typical $\mathrm{Na}^{+}-\mathrm{O}$ distance of $2.40 \AA$ (Ohtaki and Radnai, 1993), and has a solvation enthalpy of the order -440 $\mathrm{kJmol}^{-1}$. This relative weakening of the solvation shell leads one to expect that sodium might suffer from indecision when faced with the competitive attractions of the charged clay sheet and interlayer water molecules. In fact, simulations suggest that sodium prefers to form inner-sphere complexes adjacent to tetrahedral charge sites, and outer-sphere to the more shielded octahedral sites (Delville, 1991, 1992; Chang et al, 1995; Boek et al 1995b, Park and Sposito, 2000; Chavez-Paez et al, 2001a; Hensen and Smit, 2002; Malikova et al, 2004; Marry et al 2003, 2004). As with lithium, the latter are then able to participate in the formation of a diffuse population when the chemical potential of the surrounding water reservoir is sufficiently high. In the case of an inner-sphere complex, the cation is typically coordinated to 3 water molecules and 3 oxygen atoms from the clay surface.

Potassium is quite weakly solvated by $\sim 6$ water molecules at a typical $\mathrm{K}^{+}-\mathrm{O}$ distance of $2.70 \AA$ (Ohtaki and Radnai, 1993), and has a solvation enthalpy of the order $360 \mathrm{kJmol}^{-1}$. As one might expect, potassium is therefore regarded as likely to form inner-sphere complexes to both tetrahedral and octahedral charge sites, and this in a nutshell explains the inability of potassium-substituted clays to swell beyond a single molecular layer of water (Boek et al, 1995b; Newman, 1987; Chang et al, 1998; Park and Sposito, 2000). However, we note again that the $\mathrm{K}^{+}-\mathrm{O}$ coordination in the clay hydrate is not dissimilar to that in the bulk (figure 6), since in the inner-sphere complexes oxygen atoms from the clay surface are able to replace water molecules. 
As an example of a divalent cation, we consider calcium. There is still some doubt as to the solvation structure of this ion in water, but we may assume a coordination number $\sim 6$ with a typical $\mathrm{Ca}^{2+}-\mathrm{O}$ distance of $2.40 \AA$ (Ohtaki and Radnai, 1993). The solvation enthalpy of calcium in water is around $-1660 \mathrm{kJmol}^{-1}$, and this provides strong impetus for the cation to form outer-shell complexes in all swelling clay systems (Brindley and Brown, 1980; Newman, 1987, Chavez-Paez, 2001a). However, a solvated divalent cation will naturally act as a charge balancing "pillar" between two adjacent clay-sheets. This is in contrast to monovalent cations which can distribute themselves between the adjacent sheets, and precludes colloidal clay swelling.

The dynamics of interlayer cations are complex, due to the competing influences of interactions with the clay sheets and interlayer water molecules. However, as one might expect, translational diffusion parallel to the clay sheets is significantly retarded in crystalline clay hydrates relative to bulk solutions. For example, in bulk aqueous solution at room temperature $D_{\mathrm{Na}} \approx 1.5 \times 10^{-9} \mathrm{~m}^{2} \mathrm{~s}^{-1}$. This value compares to those in hydrated Nasmectites (Poinsignon et al, 1987, 1989: Chang et al, 1997): $2 \times 10^{-10} \mathrm{~m}^{2} \mathrm{~s}^{-1}$ (three-layer), 1 $\times 10^{-10} \mathrm{~m}^{2} \mathrm{~s}^{-1}$ (two-layer) and $1 \times 10^{-11} \mathrm{~m}^{2} \mathrm{~s}^{-1}$ (one-layer).

\subsection{Interlayer water in hydrated 2:1 clays}

The structure of liquid water is based on extended tetrahedral network of hydrogen bonds. In the language of the previous section, the $\mathrm{O}-\mathrm{O}$ coordination number is around 4 , with an average O-O distance of about $2.70 \AA$ A. Likewise, if we wish to compare 
with the cation solvation energy, we note that the internal energy of liquid water is around $-40 \mathrm{kJmol}^{-1}$.

We now consider how the interlayer water molecules react to the combined influences of the charge clay surfaces, interlayer ions and fellow water molecules. Perhaps the surprise here is how adept the water has shown itself at recreating the hydrogen-bonded network it enjoys in the bulk. To understand how this is achieved, we look first at the density profiles (equation 2) of oxygen and hydrogen atoms as function of distance from a clay sheet (figure 7 and 8 ). We see immediately from this that the surface water is strongly layered, with each molecule able to direct one hydrogen atom towards the surface. This effect can also be seen in figures $2 \mathrm{a}$ and $2 \mathrm{~b}$. The cation-water solvation outer-sphere complexes are in fact able to "key" onto the clay surface in this way (Skipper et al, 1991a, 1994), while the remaining hydrogen atoms are able to participate in in-plane hydrogen bonding.

The radial density in the two-molecular layer hydrate is already a close approximation to that in the bulk, albeit with distortion and breaking of hydrogen bonds (Egelstaff and Hawkins, 1980; Powell et al; 1998). The question then arises as to when (ie how far from the solid surface) will the water at the clay interface behave structurally as if it were in the bulk phase? We can answer this question in part by considering a colloidally swollen clay, such as that shown in figure $2 \mathrm{~b}$, and tracking the relaxation to the bulk water structure as a function of distance from the clay surface (de Carvalho and Skipper, 2001). In figure 8 we show the density profiles and in figure 9 the radial distribution functions of this system, with the latter also being compared with bulk water. 
We are able to identify two maxima in the water (oxygen atom) density profiles, located approximately 3 and $6 \AA$ from the clay surface. If we then focus on the radial density functions $G_{H O}(r)$ and $G_{O O}(r)$ we find that $6 \AA$ from clay surface the first nearest-neighbour environment is remarkably close to that of bulk water. However, if we look to the second nearest neighbour $\mathrm{O}-\mathrm{O}$ structure, there is a suggestion that the water suffers a longerranged perturbation to its tetrahedral network, and that this leads to a small reduction in density relative to that of pure water (de Carvalho and Skipper, 2001). The effect of the clay surface would then be to encourage the formation of low-density water (Soper and Ricci, 2000).

It has been remarked that the translational dynamics of water molecules appear to be most strongly influenced by their local structure (Swenson et al, 2000). This being the case, one would expect water to be significantly retarded in single-layer clay hydrates, but much less so in the two-layer hydrates and beyond. In broad terms, this is indeed the case. At room temperature the benchmark value is $D_{\text {water }} \approx 2.5 \times 10^{-9} \mathrm{~m}^{2} \mathrm{~s}^{-1}$ for bulk water (Hall et al 1984). In single-layer hydrates this rate of diffusion is depressed by around one order of magnitude. However, in two-layer hydrates a factor of 2 or 3 is more usual (table 2). For example, in two-layer Na-vermiculite $D_{\text {water }} \approx 8.8 \times 10^{-10} \mathrm{~m}^{2} \mathrm{~s}^{-1}$.

\subsection{Simple organic molecules in hydrated 2:1 clays}

It has long been known that simple organic molecules, such as methanol and glycol, can displace water from the interlayer region of clays (Brindley, 1966; Annabi- 
Bergaya, 1979, 1980a, 1980b, 1981; Lagaly 1981). More recently, interest has been drawn by the proposed formation of methane hydrates in clay-water-cation systems (Park and Sposito, 2003; Cygan et al 2004a) and the importance of hydrocarbon migration during burial (Titiloye and Skipper, 2001, 2005). Fundamental interest revolves around the role of the methane molecule as an archetype for apolar species at charged surfaces. In fact, it is found that the methane nestles rather snugly into the (particularly uncharged) hexagonal ring sites on the clay surface, with water molecules completing a hemispherical dome of solvation. This leads to rather unexpectedly low values for the diffusion coefficient when the concentration of methane is low (ie 4 molecules in a simulation cell similar to that shown in figure $2 \mathrm{a}$ ), of the order $3 \times 10^{-10} \mathrm{~m}^{2} \mathrm{~s}^{-1}$ in two-layer Na-smectite compared to $2.0 \times 10^{-9} \mathrm{~m}^{2} \mathrm{~s}^{-1}$ in bulk methane-water solution (Titiloye and Skipper, 2001). As we have seen, this reduction of mobility is more akin to that of interlayer cations than interlayer water. However, at higher methane concentrations and in three-layer clay hydrates, methane self-diffusion greater than in bulk methane-water solution has been calculated (Park and Sposito, 2003).

In contrast to methane, methanol and ethylene glycol are able to compete with water in the solvation shell of the interlayer cations and are able to form hydrogen bonds to their neighbours and the clay surfaces. Methanol forms predominantly one-layer solvates within sodium clays, with d-spacings of approximately $13 \AA$ (Annabi-Bergaya et al, 1980a). Recent computer simulations of interlayer methanol in sodium- and calciumsmectite confirm that methanol is able to solvate directly to the interlayer cations (Pintore et al, 2001). Ethylene glycol, on the other hand, forms two-layer solvates with d-spacing 
typically $16 \AA$ at room temperature (Brindley, 1966). In these two-layer clay-glycol complexes each glycol molecule lies on one clay surface, rather than acting as a bridge between two opposing surfaces (Bradley et al, 1963).

Our quasi-elastic neutron scattering studies methyl-group diffusion in one-layer methanol and two-layer glycol Na-vermiculite are summarized in table 2. In pure methanol we find a Fickian diffusion constant $D_{\text {trans }}=2.50 \times 10^{-9} \mathrm{~m}^{2} \mathrm{~s}^{-1}$ at $298 \mathrm{~K}-$ in excellent agreement with the previous work of Bermejo et al. (1990). In the Navermiculite, no diffusion is apparent on the QENS timescale at $200 \mathrm{~K}$. We find that the diffusion coefficient of methanol is $1.54 \times 10^{-9} \mathrm{~m}^{2} \mathrm{~s}^{-1}$ in sodium substituted vermiculite and $2.57 \times 10^{-9} \mathrm{~m}^{2} \mathrm{~s}^{-1}$. In their computer simulations of methanol in one layer Nasmectite, Pintore et al (2001) find a $D_{\text {trans }}=2.10 \times 10^{-10} \mathrm{~m}^{2} \mathrm{~s}^{-1}$ at $300 \mathrm{~K}$ and a comparable and composition. These data suggest that the increased hydrophobicity of smectite may play an important role in immobilizing methanol molecules at the clay surface. This interpretation is supported by our own QENS data at 330K (table 2).

Glycol has been studied in the bulk and in a two-layer Na-vermiculite from 100K to $350 \mathrm{~K}$ (table 2). In addition to translational diffusion, to which we return shortly, we note first that we find evidence for $Q$-independent broadening across this temperature range. There is evidence for two rotational modes, with correlation times of approximately $1 \times 10^{-12} \mathrm{~s}$ and $1 \times 10^{-11} \mathrm{~s}$ respectively in both the bulk and confined systems: these will be reported in detail elsewhere. In the vermiculite, we see the onset of translational diffusion at $275 \mathrm{~K}$ (table 2). If we then focus on the data for $325 \mathrm{~K}$, we find 
that the diffusion coefficients for bulk ethylene glycol (EG), $60 \%$ EG by weight in $\mathrm{D}_{2} \mathrm{O}$, and $60 \%$ EG by weight in $\mathrm{D}_{2} \mathrm{O}$ in Na-vermiculite are $2.82,8.97$ and $3.94 \times 10^{-10} \mathrm{~m}^{2} \mathrm{~s}^{-1}$. Interestingly therefore, EG diffuses through the clay interlayer faster than it does through the pure bulk liquid. Of course, it remains to be seen how this effect will be modified within other clay minerals, and with other interlayer cations.

\section{Conclusions}

We conclude that the interlayer pores of swelling 2:1 clays provide an ideal 2dimensional environment in which to study confined aqueous and organic fluids over a range of pore sizes. Interlayer counterions are able to mimic their local coordination to oxygen atoms, via interactions with water molecules and the clay surface. The latter lead to a propensity for weakly solvated ions, such as $\mathrm{K}^{+}$, to form "inner-sphere" complexes at the clay surface. The local hydrogen bonding environment is also found to be remarkably resilient when compared to that found in bulk water. In the clay interlayer, confined water molecules are able to form hydrogen bonds to each other and to the clays surfaces. Finally, we have discussed the way in which the simple organic molecules methane and methanol behave in the interlayer environment of hydrated clays. Here there is interesting competition between hydrophobic and hydrophilic interactions. The former appear to be strongly influenced by the nature of the clay surface, for example smectites vs vermiculites. 


\section{Acknowledgements}

We would particularly like to acknowledge the many helpful discussions with Garrison Sposito, Keith Refson and Hugh Powell. We thank NERC for financial support. 


\section{References}

Adams, M.A., Howells, W.S., Telling, M.T.F., 2001. The IRIS User Guide, $2^{\text {nd }}$ edition, Rutherford Appleton Laboratory Technical Report (RAL-TR-2001-002).

Allen, M.P., Tildesley, D.J., 1987. Computer Simulation of Liquids. Clarendon Press, Oxford, UK.

Annabi-Bergaya, F., Cruz, M. I., Gatineau, L., Fripiat, J. J., 1979. Adsorption of Alcohols by Smectites .1. Distinction between internal and external surfaces. Clay Miner 14, 249-258.

Annabi-Bergaya, F., Cruz, M. I., Gatineau, L., Fripiat, J.J., 1980a. Adsorption of Alcohols by Smectites .2. Role of the Exchangeable Cations. Clay Miner 15, 219-223.

Annabi-Bergaya, F., Cruz, M. I., Gatineau, L., Fripiat, J. J., 1980b. Adsorption of Alcohols by Smectites .3. Nature of the Bonds Clay Miner 15, 225-237.

Annabi-Bergaya, F., Cruz, M. I., Gatineau, L., Fripiat, J. J., 1981. Adsorption Of Alcohols By Smectites .4. Models Clay Minerals 16, 115-122.

Bee, M., 2003. Localized and long-range diffusion in condensed matter: state of the art of QENS studies and future prospects. Chem. Phys. 292, 121-141. 
Bérend, I., Cases, J. M., François, M., Uriot, J. P., Michot, L., Masion, A., Thomas, F., 1995. Mechanism of adsorption and desorption of water vapor by homoionic montmorillonites: 2. The $\mathrm{Li}^{+}, \mathrm{Na}^{+}, \mathrm{K}^{+}, \mathrm{Rb}^{+}$, and $\mathrm{Cs}^{+}$-exchanged forms. Clays and Clay Minerals 43, 324-336.

Bermejo, F.J., Batallan, F., Enciso, E., White, R., Dianoux, A.J., Howells, W.S., 1990. Diffusional dynamics of hydrogen bonded liquids: methanol. J. Phys.: Condens. Matter 2, 1301-1314.

Bleam, W. F., 1993. Atomic Theories of Phyllosilicates: Quantum Chemistry, Statistical Mechanics, Electrostatic Theory, and Crystal Chemistry. Rev. Geophysics 31, 5173.

Boek, E.S., Coveney, P.V., Skipper N.T., 1995a. Molecular Modelling of Clay Hydration: A Study of Hysteresis Loops in the Swelling Curves of Sodium Montmorillonites. Langmuir, 11, 4629-4631.

Boek, E.S., Coveney, P.V., Skipper, N.T., (1995b) Monte Carlo Molecular Modelling Studies of Hydrated Li-, Na-, and K-smectites: Understanding the Role of Potassium as a Clay Swelling Inhibitor. J.Am.Chem.Soc., 117, 12608-12617.

Boek, E.S., Sprik, M., 2003. Ab initio molecular dynamics study of the hydration of a sodium smectite clay. J. Phys. Chem. B 107, 3251-3256. 
Bounds, D.G., 1985. A molecular dynamics study of the structure of water around the ions $\mathrm{Li}^{+}, \mathrm{Na}^{+}, \mathrm{K}^{+}, \mathrm{Ca}^{2+}, \mathrm{Ni}^{2+}$ and $\mathrm{Cl}^{-}$. Mol.Phys. 54, 1335-1355.

Bradley, W.F., Weiss, E.J., Rowland, R.A., 1963. A glycol-sodium vermiculite vermiculite complex. Proc. Tenth Nat. Conf. on Clays and Clay Minerals, Pergamon Press, New York, 117-122.

Brindley, G., 1966. Ethylene glycol and glycerol complexes of smectites and vermiculites. Clay Minerals 6, 237-260.

Brindley, G.W., Brown, G., 1980. Crystal Structures of Clay Minerals and their X-ray Identification. Mineralogical Society, London, UK.

Brodholt, J., Wood, B., (1993) Simulations of the structure and thermodynamic properties of water at elevated pressures and temperatures. J.Geophys.Res: Solid Earth, 98, 513-536.

Cases, J. M., Bérend, I., François, M., Uriot, J. P., Michot L. J., Thomas F., 1997. Mechanism of adsorption and desorption of water vapor by homoionic montmorillonite: 3. The Mg2+, Ca2+, Sr2+ and Ba2+ exchanged forms. Clays and Clay Minerals 45, 8-22.

de Carvalho, R.J.F.L., Skipper, N.T., 2001. Atomistic computer simulation of the clayfluid interface in colloidal laponite. J. Chem. Phys. 114, 3727-3733. 
Cebula, D. J., Thomas, R. K., Middleton, S., Ottewill, R. H., White, J. W., 1979. Neutrondiffraction from clay-water systems. Clays \& Clay Minerals 27, 39-52.

Cebula, D. J., Thomas, R. K., White, J. W., 1981. Diffusion of water in li-montmorillonite studied by quasi-elastic neutron-scattering. Clay Clay Miner 29, 241-248.

Chandrasekhar, J., Spellmeyer, D.C., Jorgensen W.L., 1984. Energy Component Analysis for Dilute Aqueous Solutions of $\mathrm{Li}^{+}, \mathrm{Na}^{+}, \mathrm{F}^{-}$and $\mathrm{Cl}^{-}$ions. J.Am.Chem.Soc., 106, 903-910.

Chang, F-R.C., Skipper, N.T. Sposito, G., 1995. Computer Simulation of Interlayer Molecular Structure in Sodium Montmorillonite Hydrates. Langmuir, 11, 27342741.

Chang, F-R.C., Skipper, N.T., Sposito, G., 1997. Monte Carlo and molecular dynamics simulations of interfacial structure in lithium montmorillonite hydrates. Langmuir 13, 2074-2082.

Chang, F-R.C., Skipper, N.T., Sposito, G., 1998. Monte Carlo and molecular dynamics simulations of electrical double-layer structure in potassium montmorillonite hydrates. Langmuir 14, 1201-1207.

Chavez-Paez, M., de Pablo, L., de Pablo, J.J, 2001a. Monte Carlo simulations of Camontmorillonite hydrates. J.Chem.Phys. 114, 10948-10953. 
Chavez-Paez, M., van Workum, K., de Pablo, L., de Pablo, J.J., 2001b. Monte Carlo simulations of Wyoming sodium montmorillonite hydrates. J. Chem. Phys. 114, 1405-1413.

Cygan, R.T., Guggenheim, S., van Groos A.F.K., 2004a. Molecular models for the intercalation of methane hydrate complexes in montmorillonite clay. J Phys Chem B 108, 15141-15149.

Cygan, R.T., Liang, J.J., Kalinichev, A.G., 2004b. Molecular models of hydroxide, oxyhydroxide, and clay phases and the development of a general force field. $\mathrm{J}$ Phys Chem B 108, 1255-1266.

Cygan, R.T., 2001. Molecular modeling in mineralogy and geochemistry. Rev Mineral Geochem 42, 1-35.

Delville, A., 1991. Modelling the Clay-Water Interface. Langmuir, 7, 547-555.

Delville, A., 1992. Structure of Liquids at a Solid Interface: An Application to the Swelling of Clay by Water. Langmuir, 8, 1796-1805.

Delville, A., 1993a. Structure and Properties of Confined Liquids: A Molecular Model of the Clay-Water Inteface. J.Phys.Chem., 97, 9703-9712.

Delville, A., Sokolowski, S., 1993b. Adsorption of Vapour at a Solid Interface: A Molecular Model of Clay Wetting. J.Phys.Chem., 97, 6261-6271. 
Enderby, J.E., Neilson G.W., 1981. The structure of electrolyte solutions. Rep. Prog.Phys., 44, 593-643.

Enderby, J.E., Cummings, S., Herdman, G.J., Neilson, G.W., Salmon, P.S., Skipper, N.T., 1987. Diffraction and the study of Aqua-ions. J. Phys. Chem., 91, 5851-5858.

Finney, J.L., Quinn, J.E., Baum, J.O., 1986. The water dimer potential surface. Water Science Reviews, 1, 93.

Frenkel, D., Smit, B., 1996. Understanding Molecular Simulation. Academic Press, San Diego, USA.

Glaeser, R., Méring, J., 1968. Domaines d’hydration homogène des smectites. C. r. hebd. Séan. Acad. Sci. Paris 267, 463-466.

Greathouse, J.A., Refson, K., Sposito, G., 2000. Molecular dynamics simulation of water mobility in magnesium-smectite hydrates. J Am Chem Soc 122, 11459-11464.

Güven, N. 1992. Molecular Aspects of Clay-Water Interactions. Clay Water Interface and its Rheological Implication, editors N.Guven and R.M.Pollastro, Volume 4, CMS Workshop Lectures, The Clay Minerals Society, Boulder, Colorado, USA.

Hawkins, R. K., Egelstaff, P. A., 1980. Interfacial water-structure in montmorillonite from neutron-diffraction experiments. Clays \& Clay Minerals 28, 19-28. 
Hempelmann, R., 2000. Quasielastic neutron scattering and solid state diffusion, Clarendon, Oxford.

Hensen, E.J.M., Smit, B., 2002. Why Clays Swell. J. Phys. Chem. B, 106, 12664-12667.

Howells, W. S., 1996. Technical Report, Rutherford Appleton Laboratory, RAL-TR-96006.

Jorgensen, W.L., Chandrasekhar J., Madura J., Impey R.W., Klein M.L., 1983. Comparison of simple potential functions for modelling water. J. Chem. Phys., 79, 926-935.

Jorgensen, W.L., 1981. Transferable intermolecular potential functions for water, alcohols and ethers. Application to liquid water. J. Am. Chem. Soc., 103, 335-340.

Jorgensen, W.L., 1984. Optimised Intermolecular Potential Functions for liquid hydrocarbons. J. Am. Chem. Soc., 106, 6638-6646.

Karaborni, S., Smit, B., Heidug, W., Urai, J., van Oort, E., 1996. The Swelling of Clays: Molecular of the Hydration of Montmorillonite. Science, 271, 1102-1104.

Kubicki, J.D., Bleam, W.F., 1998. Molecular modeling of clays and mineral surfaces: a short course. CMS Workshop 12. Clay Minerals Society, Boulder, USA.

Kuyucak, S., Andersen, O.S., Chung, S-H., 2001. Models of permeation in ion channels. Rep. Prog. Phys. 64, 1427-1472. 
Lagaly, G., 1981. Characterisation of clays by organic compounds. Clay Minerals 16, 121.

Mahoney, M.W., Jorgensen, W.L., 2000. A five-site model for liquid water and the reporduction of the density anomaly by rigid, nonpolarizable potential functions. J. Chem. Phys. 112, 8910-8922.

Malikova, N., Marry, V., Dufreche J.F., Turq P., 2004. Temperature effect in a montmorillonite clay at low hydration-microscopic simulation. Mol Phys 102, 1965-1977.

Marry, V., Turq P., 2003. Microscopic simulations of interlayer structure and dynamics in bihydrated heteroionic montmorillonites. J Phys Chem B 107, 1832-1839.

Marry, V., Turq, P., Cartailler, T., Dufreche, JF., 2002. Microscopic simulation of structure and dynamics of water and counterions in a monohydrated montmorillonite. J Chem Phys 117, 3454-3463.

Neilson, G.W., Enderby, J.E., 1989. Co-ordination of metal aquaions. Adv. Inorg. Chem., 34, 196-218.

Newman, A.C.D., 1987. Chemistry of Clays and Clay Minerals. Wiley, New York, USA.

Norrish, K., 1954. The swelling of montmorillonite. Discuss. Faraday Soc. 18, 120-132.

North, F.K., 1990. Petroleum Geology. Unwin-Hyman, Boston, USA. 
Ohtaki, H., Radnai T., 1993. Structure and dynamics of hydrated ions. Chem. Rev., 93, 1157-1204.

Park, S-H,. Sposito, G., 2000. Monte Carlo simulation of total radial distribution functions for interlayer water in Li-, Na-, and K-montmorillonite hydrates. J. Phys. Chem. B 104, 4642-4648.

Park, S-H., Sposito, G., 2002. Structure of water adsorbed on a mica surface Phys Rev Lett. 89. 85501-85505.

Park, S-H., Sposito, G., 2003. Do montmorillonite surfaces promote methane hydrate formation? Monte Carlo and molecular dynamics simulations. J Phys Chem B 107, 2281-2290.

Pintore, M., Deiana, S., Demontis, P., Manunza, B., Suffritti, G.B., Gessa, C., 2001. Simulations of interlayer methanol in Ca- and Na-saturated montmorillonites using molecular dynamics. Clay Clay Miner 49, 255-262.

Poinsignon, C., Estrade, H., Conard, J., Dianoux, A.J., 1987. Water dynamics in the clay water system. A quasielastic neutron scattering study. Proc. Int. Clay Conf., Denver 1985, Schultz L.FG., Van Olphen H., Mumpton F.A. Eds, The Clay Minerals Society, Bloomington (Indiana), 284-291.

Poinsignon, C., Estrade, H., Conard, J., Dianoux, A. J., 1989. Structure and Dynamics of Intercalated Water in Clays Minerals. Physica B 156 \& 157, 140-144. 
Porion P., Al Mukhtar, M., Faugére, A.M., Pellenq, R.J.M., Meyer, S., Delville A., 2003. Water self diffusion within nematic dispersions of nanocomposites: a multiscale analysis of ${ }^{1} \mathrm{H}$ pulsed gradient spin-echo NMR measurements. J. Phys. Chem. B 107, 4012-4023.

Powell, D.H., Fischer H.E., Skipper N.T., 1998. The structure of interlayer water in Limontmorillonite studied by neutron diffraction with isotopic substitution. J. Phys. Chem.B, 102, 10899-10905.

Sears, V. F., 1966. Theory of cold neutron scattering by homonuclear diatomic liquids. I. Free rotation. Can. J. Phys. 44, 1299.

Shroll, R.M., Smith D.E., 1999. Molecular dynamics simulations in the grand canonical ensemble: application to clay mineral swelling. J. Chem. Phys., 111, 9025-9033.

Siqueira de, A., Skipper, N.T., Coveney, P.V., Boek, E.S., 1997. Computer Simulation Evidence for Enthalpy driven Dehydration of Clays Under Sedimentary Basin Conditions. Mol. Phys., 92, 1-6.

Skipper, N.T., Soper, A.K., McConnell J.D.C., 1991a. The structure of interlayer water in vermiculite. J. Chem. Phys., 94, 5751-5760.

Skipper, N.T., Refson K., McConnell, J.D.C., 1991b. Computer simulation of interlayer water in 2:1 clays. J. Chem. Phys., 94, 7434-7445. 
Skipper, N.T., Soper, A.K., Smalley M.V., 1994. Neutron diffraction study of calcium vermiculite - hydration of calcium ions in a confined environment. J. Phys. Chem., 98, 942-945.

Skipper, N.T., Chang, F-R.C., Sposito G., 1995a. Monte Carlo simulation of interlayer molecular structure in swelling clay minerals. 1. Methodology. Clays Clay Miner., 43, 285-293.

Skipper, N.T., Chang, F-R.C., Sposito, G., 1995b. Monte Carlo simulation of interlayer molecular structure in swelling clay minerals. 2. Monolayer Hydrates. Clays Clay Miner., 43, 294-303.

Skipper, N.T., Smalley, M.V., Williams, G.D., Soper A.K., Thompson, C.H., 1995c. Direct measurement of the electric double-layer structure in hydrated lithium vermiculite clays by neutron diffraction. J. Phys. Chem., 99, 14201-14204 .

Smith, D.E., 1998. Molecular computer simulation of the swelling properties and interlayer structure of cesium montmorillonite. Langmuir 14, 5959-5967.

Soper, A.K., Ricci, M.A., (2000) The structure of high density and low-density water. Phys. Rev. Lett. 84, 2881-2884.

Sposito, G., Prost, R., 1982. Structure of water adsorbed on smectites. Chem. Rev., 82, 553-573. 
Sposito, G., Skipper, N.T., Sutton, R., Park, S-H., Chang, F-R., Soper, A.K., Greathouse, J.A., 1999. Surface Geochemistry of the clay minerals. Proc. Natl. Acad. Sci. USA, 96, 3358-3364.

Squires, G.L., 1978. Introduction to the Theory of Thermal Neutron Scattering (Cambridge, New York, Cambridge University Press.

Swenson, J., Bergman, R., Howells, W.S., 2000. Quasielastic neutron scattering of twodimensional water in vermiculite clay. J. Chem. Phys. 117. 2873-2879.

Teppen, B.J., Yu, C-H., Miller, D.M., Schäfer, L., 1998. Molecular dynamics simulations of sorption of organic compounds at the clay mineral/aqueous solution interface. Journal Comput Chem 19, 144-153.

Titiloye, J.O., Skipper, N.T., 2001. Molecular dynamics simulation of methane in sodium montmorillonite clay hydrates at elevated pressures and temperatures. Mol. Phys. 99, 899-906.

Titiloye, J.O., Skipper, N.T., 2005. Monte Carlo and molecular dynamics simulations of methane in potassium montmorillonite clay hydrates at elevated pressures and temperatures. J. Colloid Interface Science 282, 422-427.

Tossell J.A., 1995. Mineral Surfaces: Theoretical Approaches. Edited by Vaughan D.J. and Pattrick R.A.D. Chapman and Hall, London, UK. 
Tuck, J.J., Hall, P.L, Hayes, M.H.B., Ross, D.K., Poinsignon C., 1984. Quasi elastic neutron scattering studies of the dynamics of intercalated molecules in charge deficient layer siliciates. J. Chem. Soc. Faraday Trans. 1. 80, 309-324.

Tuck, J. J., Hall, P. L., Hayes, M. H. B., Ross, D. K., Hayter, J. B., 1985. J. Chem. Soc. Faraday Trans. 1. 81, 833-846 .

Vlot, M.J., Huinink, J., van der Eerden, J.P., 1999. Free energy calculations on systems of rigid molecules: an application to the TIP4P model of $\mathrm{H}_{2} \mathrm{O}$. J. Chem. Phys. 110, 55-61.

Watanabe, K., Klein, M.L., 1989. Effective pair potentials and the properties of water. Chem. Phys., 131, 157-167

Williams, G.D., Soper, A.K., Skipper, N.T., Smalley, M.V., 1998. High resolution structural study of interfacial fluids in vermiculite clays. J. Phys. Chem. B, 102, 8945-8949.

Wilson, J., Cuadros, J., Cressey, G., 2004. An in situ time-resolved XRD-PSD investigation into Na-montmorillonite interlayer and particle rearrangement during dehydration. Clays and Clay Minerals, 52, 180-191. 


\section{Figure Captions}

Figure 1. The structure of an uncharged talc sheet, showing projections in the $a b$ - and $c a-$ planes. Octahedral magnesium ions are small dark spheres, tetrahedral silicon ions are large grey spheres, oxygen atoms are large feint spheres, and hydroxyl groups are the large bold spheres recessed into the hexagonal cavity sites. The dimensions of the clay sheet shown here are $18.24 \AA \times 21.12 \AA \times 6.54 \AA$ : this is typical of the slabs used in computer simulation unit cells and contains sixteen $\mathrm{Mg}_{3} \mathrm{Si}_{4} \mathrm{O}_{10}(\mathrm{OH})_{2}$ units. For convenience, the $a b$ projection shows only the top half of the layer.

Figure 2. Molecular graphics snapshots of hydrated sodium smectite. a. A two-molecular layer “crystalline” hydrate, of layer spacing $15 \AA \AA$. b. A colloidally swollen hydrate, with layer spacing of $35 \AA$.

Figure 3. a. The crystalline swelling of Na-smectites as a function of water vapour pressure, $P / P_{0}$. Solid circles - Na-montmorillonite, open circles - Na-beidelite, and crosses - Na-hectorite. The data show the step-wise expansion from dry clay to a one- and two-layer hydrate. (after Glaeser and Méring, 1968). b. Colloidal swelling of Namontmorillonite immersed in $\mathrm{NaCl}$ (crosses) or $\mathrm{Na}_{2} \mathrm{SO}_{4}$ (circles) solution, showing the linear dependence on reciprocal square root of concentration (after Norrish, 1954).

Figure 4. Calculated swelling pressure and average number of molecules in Namontmorillonite, as a function of layer spacing. The stable states of Na-montmorillite are indicated by the arrows, and show excellent agreement with the experimental data shown 
in figure 3a. Reproduced with permission from Chávez-Páez et al (2001). Copyright 2001 American Institute of Physics.

Figure 5. Ion speciation at clay surfaces: schematic diagram based on Sposito et al (1999).

Figure 6. Ion solvation in a swelling clay. The data show the calculated radial densities, $G_{\mathrm{MO}}(\mathrm{r})$, for lithium, sodium and potassium ions in a two-molecular layer smectite hydrate and bulk solution.

Figure 7. The structure of water in a crystalline swollen clay. Density profiles of water and cations in a two-molecular layer sodium-smectite hydrate: see figure $2 \mathrm{a}$.

Figure 8. The structure of water in a colloidally swollen clay. Interlayer particle density profiles for Na-hectorite hydrate, of layer spacing $34 \AA$. The profiles are oxygen - solid line, hydrogen - dot/dash line, and sodium - dash line. Note that the counterions are concentrated near the clay surface, as hydrated complexes, and that there is evidence for three structured layers of water at the interface. Even at the center of the interlayer region the water density has not recovered to its bulk value, shown as the horizontal line (de Carvalho and Skipper, 2000). The clay surfaces are represented by the shaded vertical bars. Copyright 2000 American Institute of Physics.

Figure 9 . The structure of water in a colloidally swollen clay. a. $\mathrm{G}_{\mathrm{HO}}(\mathrm{r})$ and b. $\mathrm{G}_{\mathrm{OO}}(\mathrm{r})$ as a function of distance from a clay surface in a colloidally swollen sodium-smectite hydrate, 
and in water bulk (see figure 2b and figure 8). The figure in the legend give the distances in $\AA$ from a clay surface.

Figure 10. Quasi-elastic neutron scattering (QENS) from glycol $\left(\mathrm{CH}_{2} \mathrm{OD}\right)_{2}$. a. Broadening as a function of temperature in two-layer Na-vermiculite with a layer spacing of $16 \AA$. b. Full width half maximum vs $Q^{2}$ for glycol $\left(\mathrm{CH}_{2} \mathrm{OD}\right)_{2}$ in selected samples, showing experimental data (symbols) and fits to equation 11. Fit parameters are presented in table 2 . 


\section{Tables}

Table 1: Neutron scattering lengths, $b$, and incoherent cross-sections, $\sigma_{\text {inc }}$, of some atoms encountered in clay systems. Note that $\mathrm{H}$ and $\mathrm{D}$ have radically different neutron scattering lengths, and the $\mathrm{H}$ has by far the biggest incoherent scattering cross-section.

\begin{tabular}{llllllllll} 
Species & $\mathrm{H}$ & $\mathrm{D}$ & $\mathrm{O}$ & $\mathrm{Ca}$ & $\mathrm{Na}$ & $\mathrm{Mg}$ & $\mathrm{Si}$ & $\mathrm{Al}$ & $\mathrm{C}$ \\
\hline$b / \mathrm{fm}$ & -3.74 & 6.67 & 5.81 & 4.90 & 3.63 & 5.38 & 4.15 & 3.45 & 6.64 \\
$\sigma_{\text {inc }} /$ barn & 80.26 & 2.05 & 0.0008 & 0.05 & 1.62 & 0.08 & 0.004 & 0.008 & 0.001
\end{tabular}


Table 2. Summary of diffusion data for water molecules cations in hydrated montmorillonite clays, obtained by computer simulation.

\begin{tabular}{|c|c|c|c|c|c|}
\hline Sample & $\begin{array}{l}\text { Temperature } \\
(\mathrm{K})\end{array}$ & $\begin{array}{l}\text { Labelled } \\
\text { molecule }\end{array}$ & $\begin{array}{l}\text { Translational } \\
\text { diffusion } \\
\text { coefficent }\left(\mathrm{m}^{2} \mathrm{~s}^{-1}\right)\end{array}$ & $\begin{array}{l}\text { Residence } \\
\text { time (ps) }\end{array}$ & $\begin{array}{l}\text { Mean } \\
\text { jump } \\
\text { length }(\AA)\end{array}$ \\
\hline 2L: $\mathrm{H}_{2} \mathrm{O}$ Na-vermiculite & 265 & $\mathbf{H}_{2} \mathrm{O}$ & $5.5 \times 10^{-10}$ & 16.0 & 2.3 \\
\hline 2L: $\mathrm{H}_{2} \mathrm{O}$ Na-vermiculite & 300 & $\mathbf{H}_{2} \mathrm{O}$ & $8.8 \times 10^{-10}$ & 2.3 & 1.1 \\
\hline Bulk: $\mathrm{H}_{2} \mathrm{O}$ & 300 & $\mathbf{H}_{2} \mathrm{O}$ & $2.5 \times 10^{-10}$ & 1.4 & 1.4 \\
\hline 1L: $\mathrm{CH}_{3} \mathrm{OD}$ Na-vermiculite & 300 & $\mathrm{CH}_{3} \mathrm{OD}$ & $1.54 \times 10^{-9}$ & 7.5 & 2.6 \\
\hline 1L: $\mathrm{CH}_{3} \mathrm{OD}$ Na-vermiculite & 330 & $\mathrm{CH}_{3} \mathrm{OD}$ & $2.59 \times 10^{-9}$ & 3.8 & 2.4 \\
\hline 1L: $\mathrm{CH}_{3} \mathrm{OD}$ Na-smectite & 330 & $\mathrm{CH}_{3} \mathrm{OD}$ & $8.88 \times 10^{-10}$ & 3.5 & 1.4 \\
\hline Bulk: $\mathrm{CH}_{3} \mathrm{OD}$ & 300 & $\mathrm{CH}_{3} \mathrm{OD}$ & $2.49 \times 10^{-9}$ & & \\
\hline $\begin{array}{l}2 \mathrm{~L}: 60 \%\left(\mathrm{CH}_{2} \mathrm{OD}\right)_{2} \text { in } \mathrm{D}_{2} \mathrm{O} \\
\text { Na-vermiculite }\end{array}$ & 325 & $\left(\mathrm{CH}_{2} \mathrm{OD}\right)_{2}$ & $4.4 \times 10^{-10}$ & 9.1 & 1.5 \\
\hline $\begin{array}{l}2 \mathrm{~L}: 60 \%\left(\mathrm{CH}_{2} \mathrm{OD}\right)_{2} \text { in } \mathrm{D}_{2} \mathrm{O} \\
\text { Na-vermiculite }\end{array}$ & 350 & $\left(\mathrm{CH}_{2} \mathrm{OD}\right)_{2}$ & $7.7 \times 10^{-10}$ & 7.0 & 1.8 \\
\hline Bulk: $60 \%\left(\mathrm{CH}_{2} \mathrm{OD}\right)_{2}$ in $\mathrm{D}_{2} \mathrm{O}$ & 275 & $\left(\mathrm{CH}_{2} \mathrm{OD}\right)_{2}$ & $1.0 \times 10^{-10}$ & 17.8 & 1.0 \\
\hline Bulk: $60 \%\left(\mathrm{CH}_{2} \mathrm{OD}\right)_{2}$ in $\mathrm{D}_{2} \mathrm{O}$ & 325 & $\left(\mathrm{CH}_{2} \mathrm{OD}\right)_{2}$ & $9.8 \times 10^{-10}$ & 2.4 & 0.82 \\
\hline Bulk: $\left(\mathrm{CH}_{2} \mathrm{OD}\right)_{2}$ & 325 & $\left(\mathrm{CH}_{2} \mathrm{OD}\right)_{2}$ & $1.5 \times 10^{-10}$ & 10.4 & 1.0 \\
\hline
\end{tabular}


Figure 1
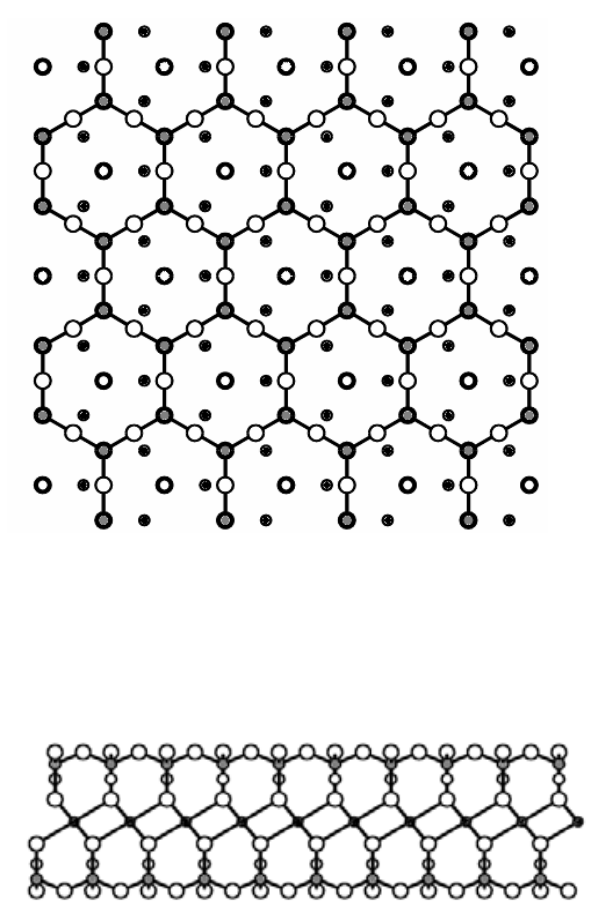
Figure 2a

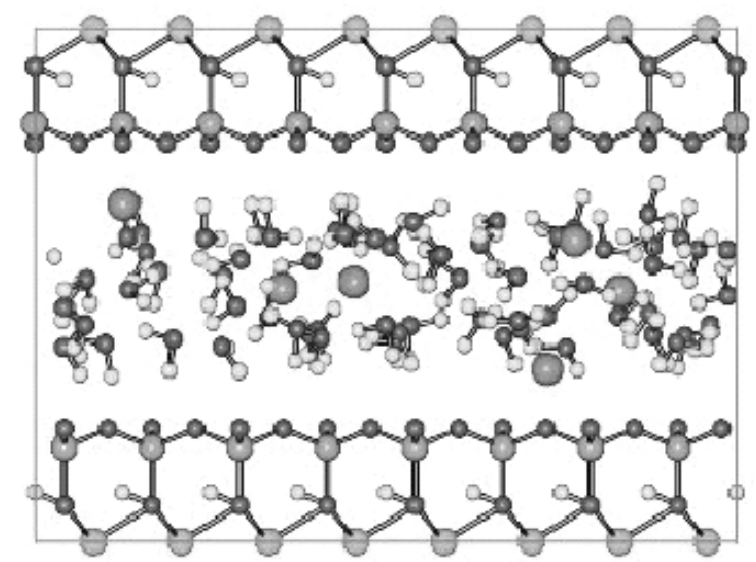


Figure 2b

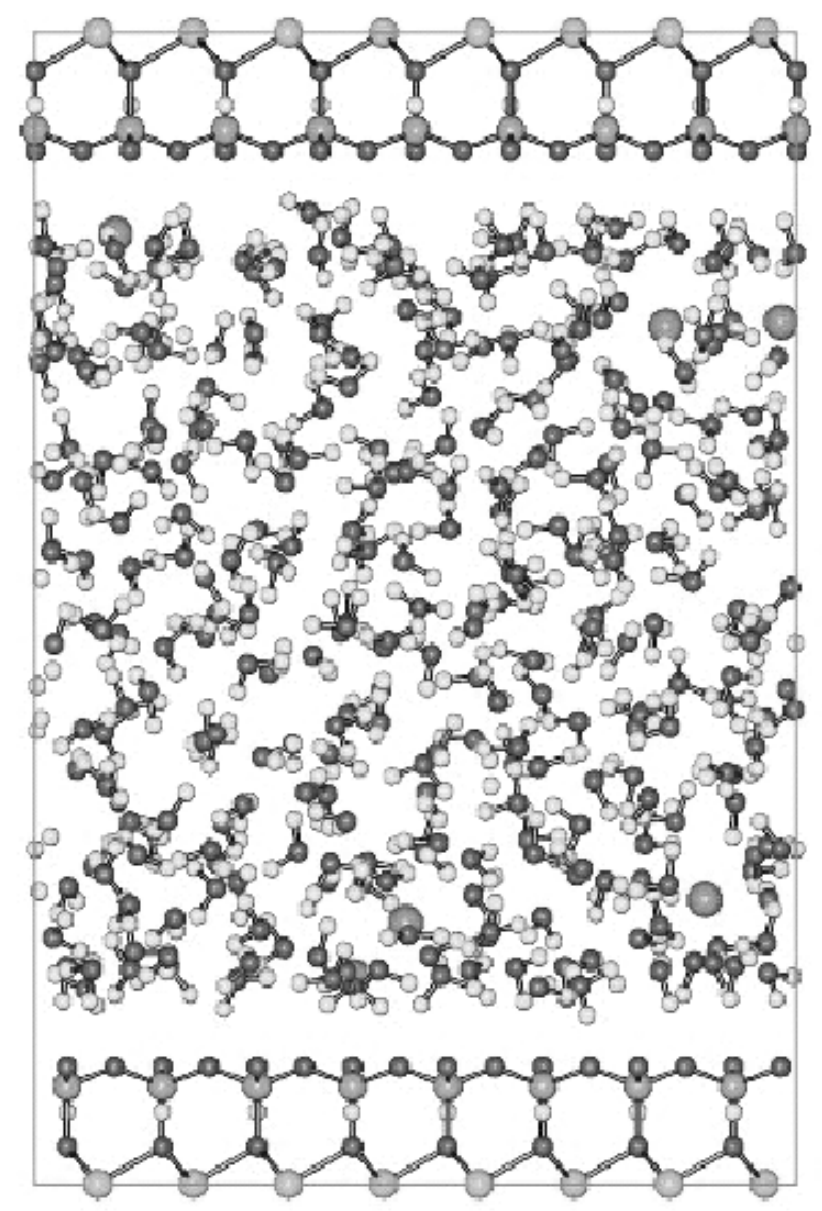


Figure 3a

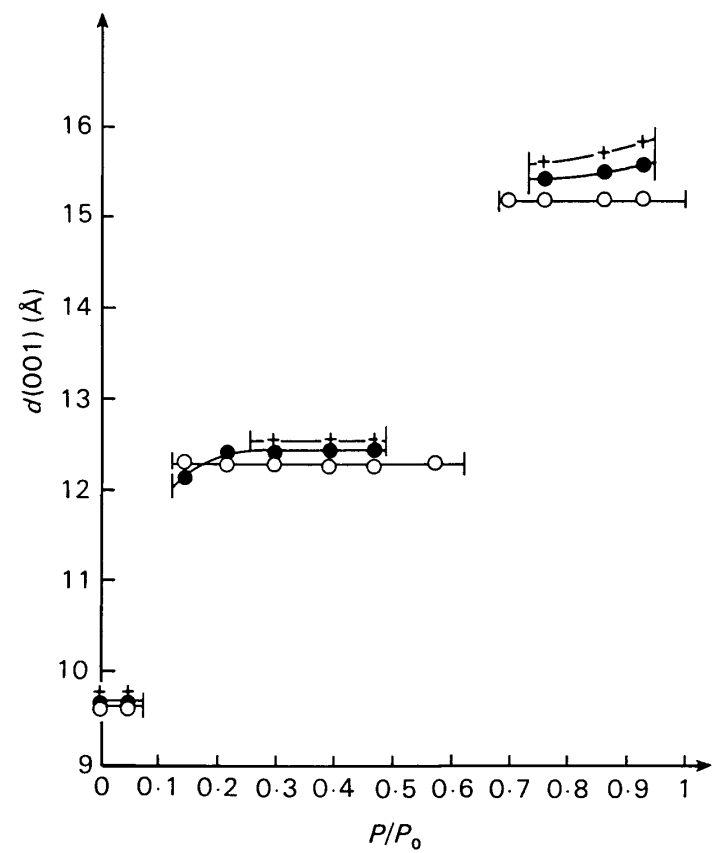


Figure $3 b$

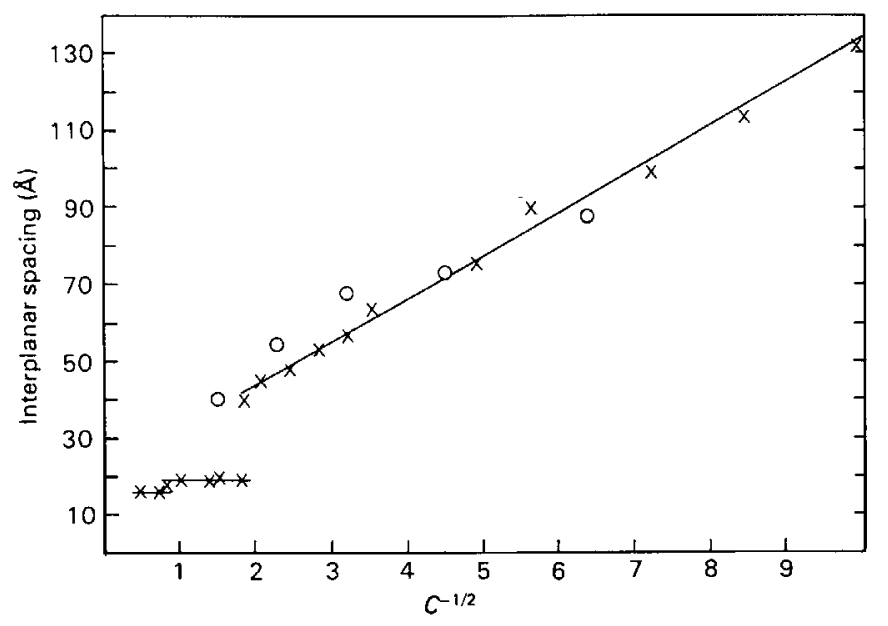


Figure 4

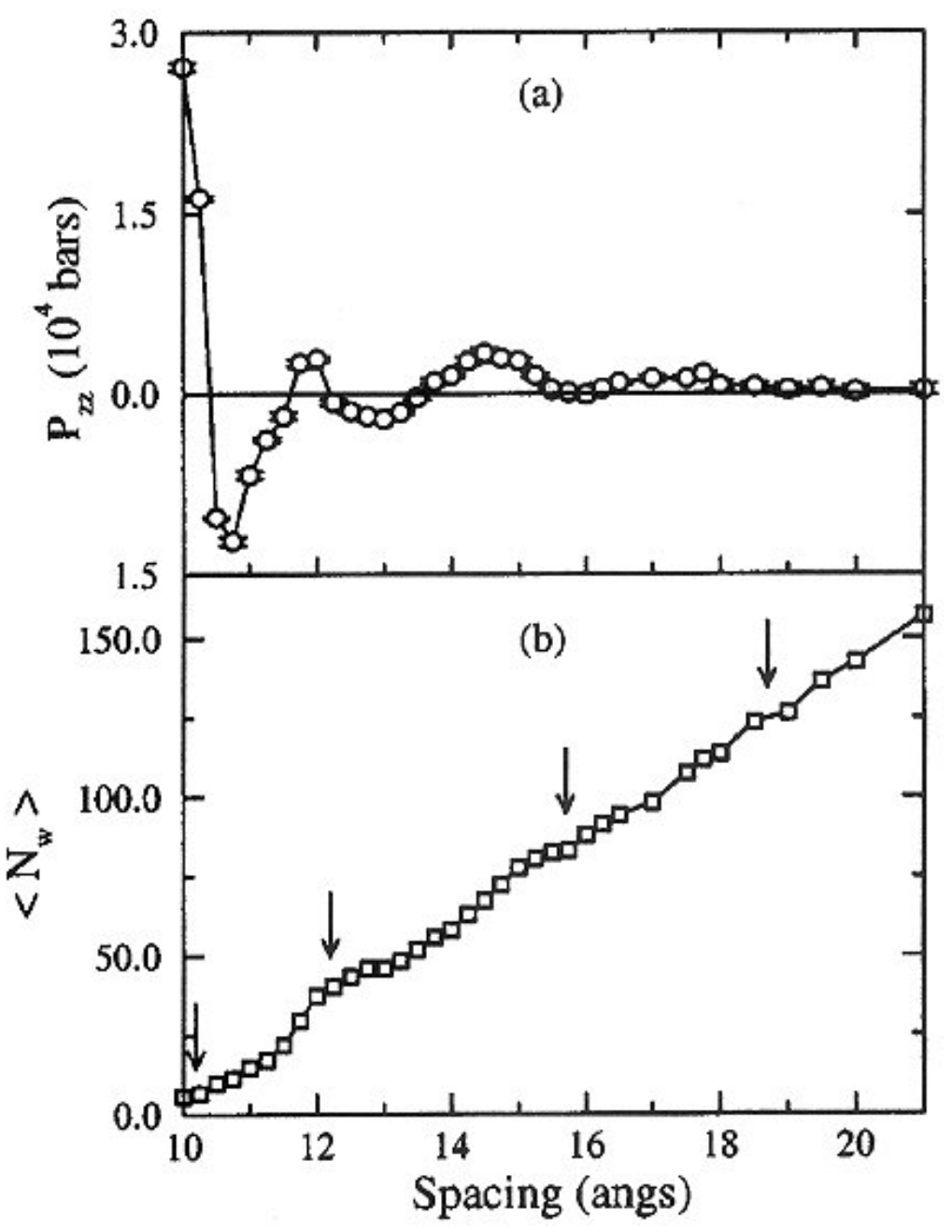


Figure 5

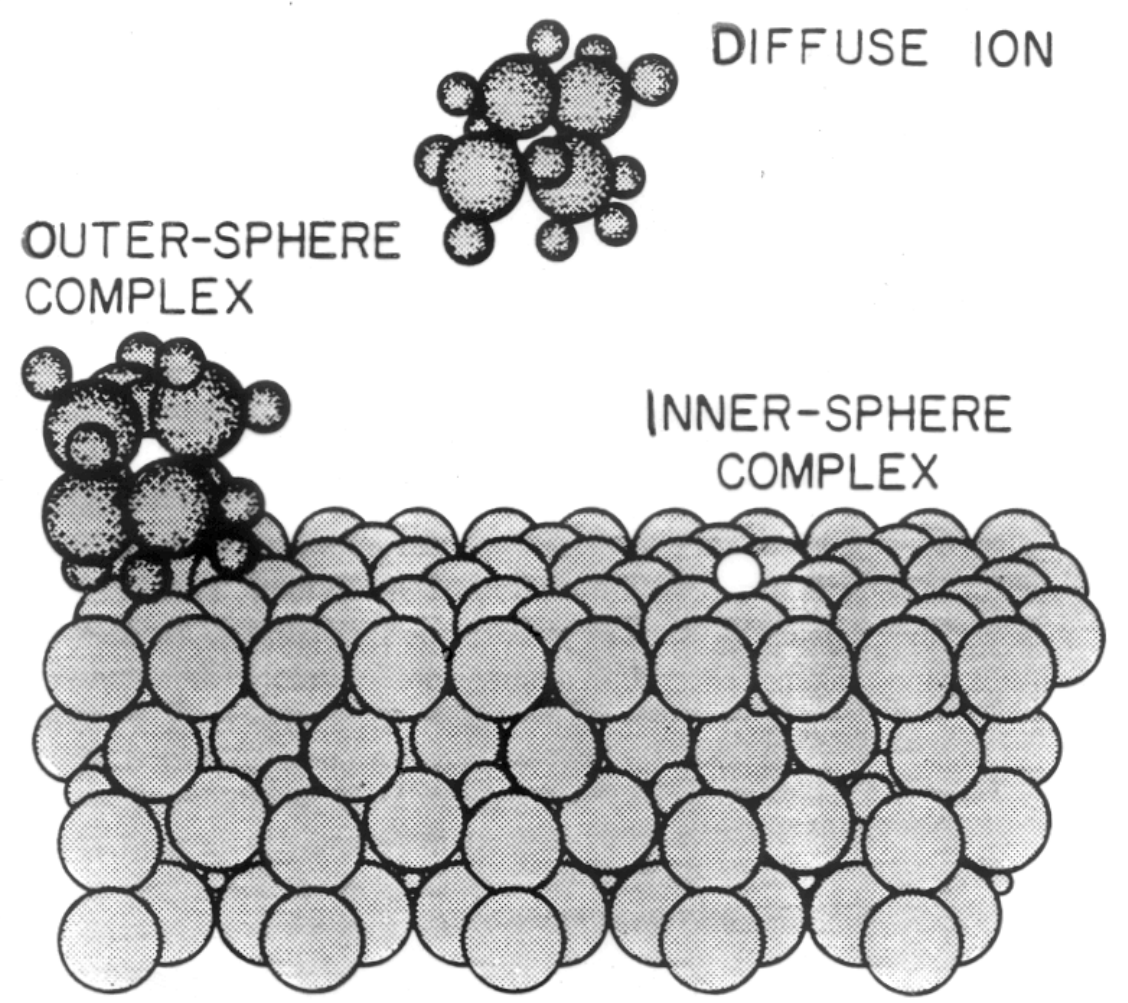


Figure 6

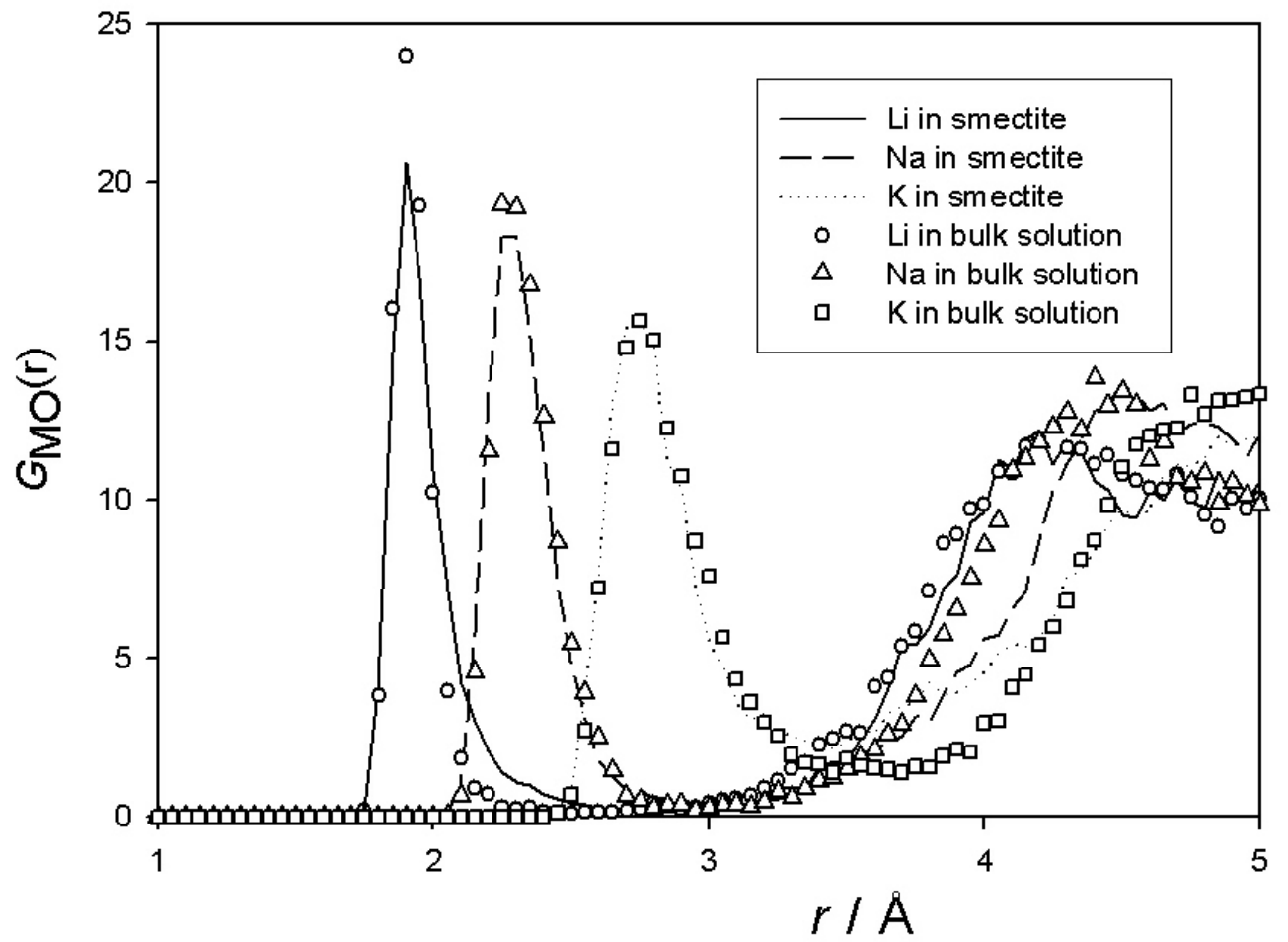


Figure 7

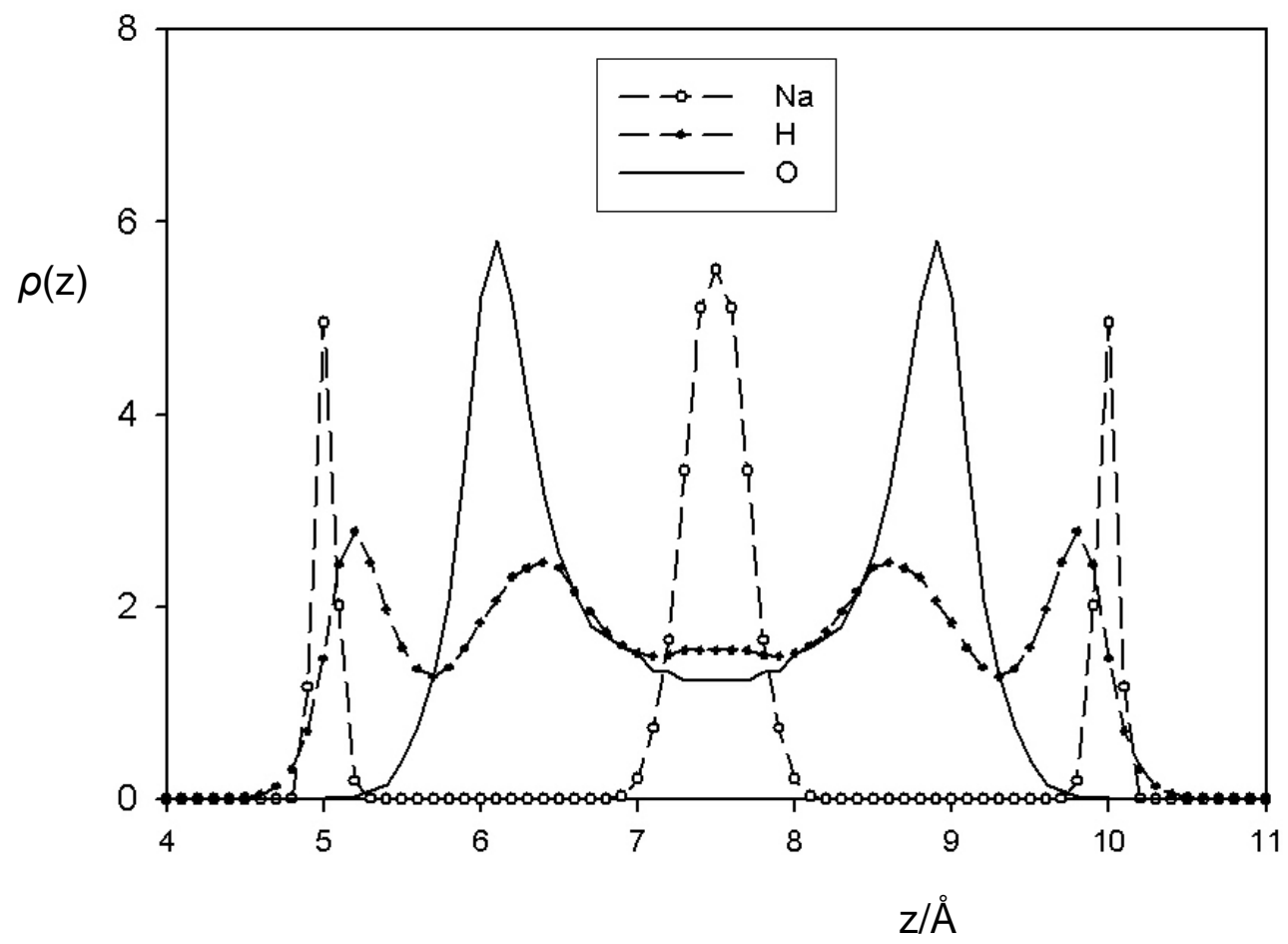


Figure 8

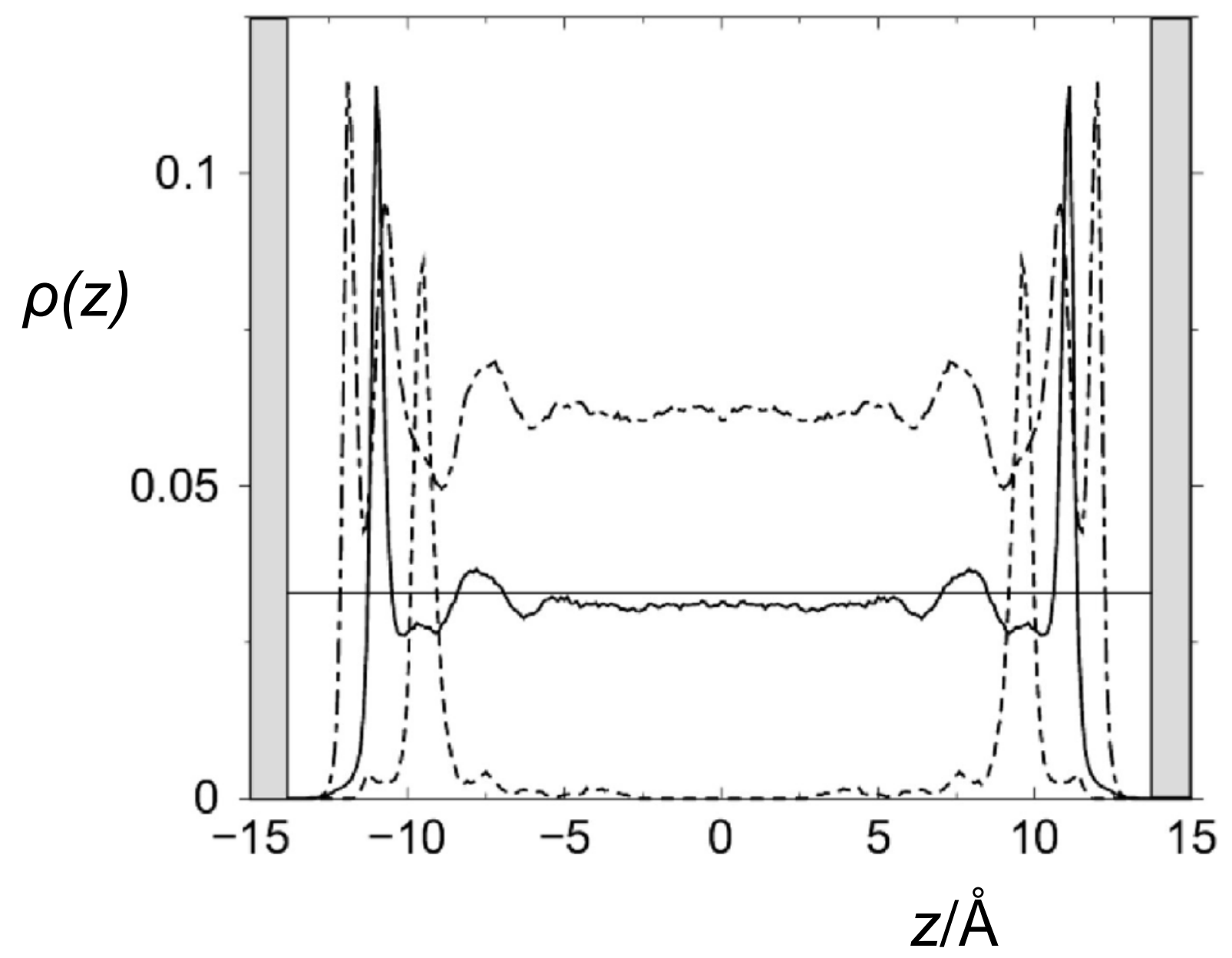


Figure 9a

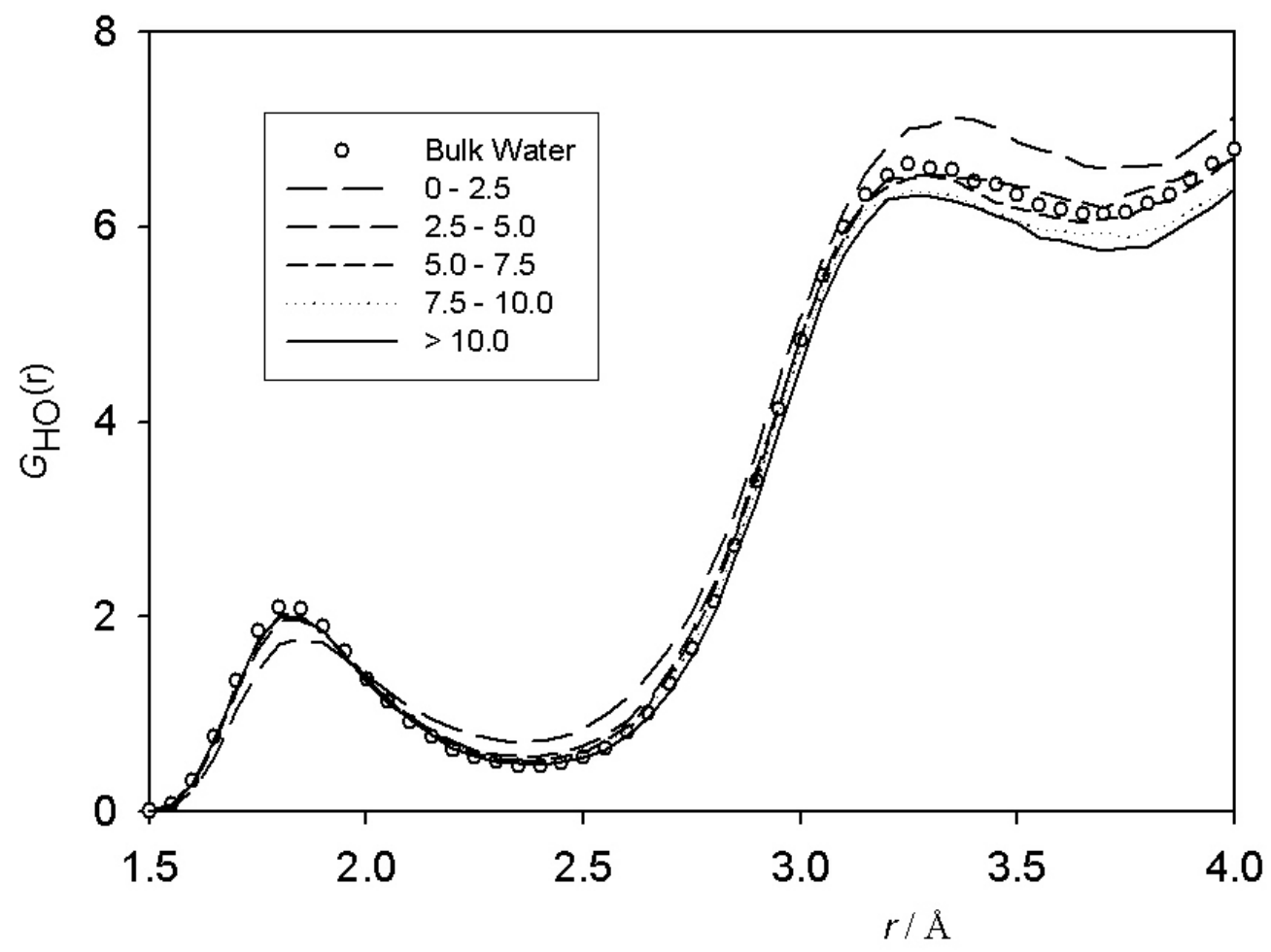


Figure 9b

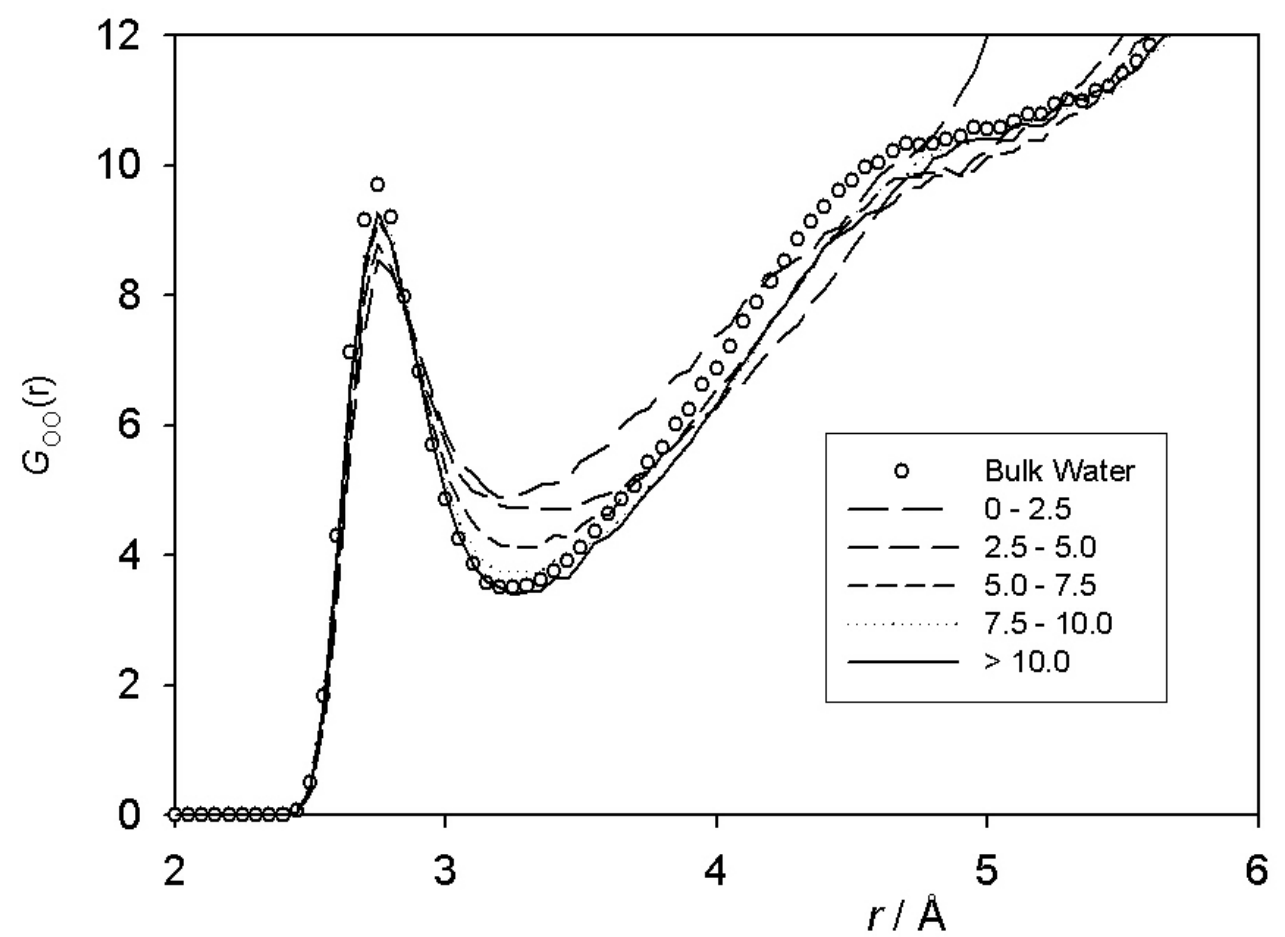


Figure 10a

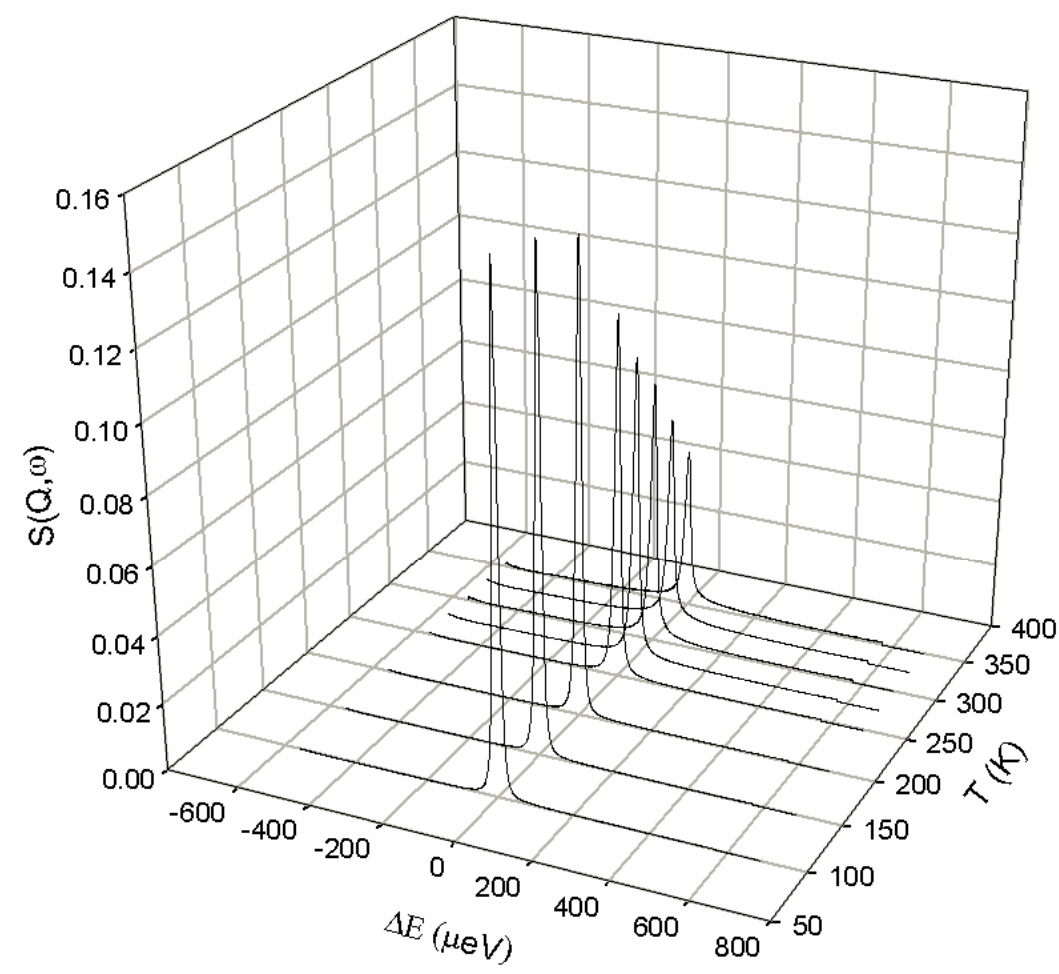


Figure 10b

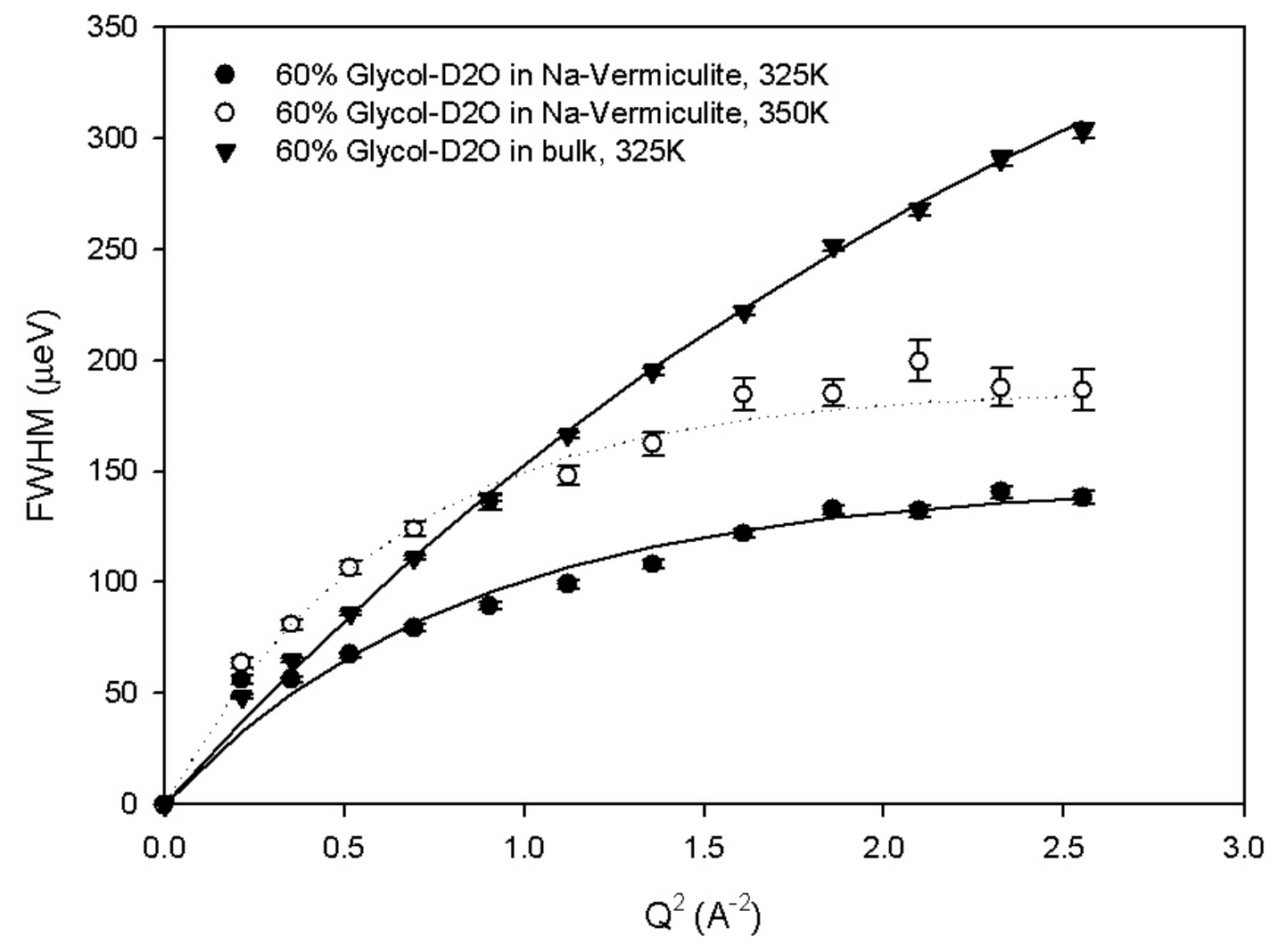

